\title{
HEAT TRANSFER ANALYSIS FOR FIXED CST AND RF COLUMNS
}

Si Young Lee

October 2007

Washington Savannah River Company

Savannah River National Laboratory

Aiken, SC 29808

Prepared for the U.S. Department of Energy

Under Contract No. DE-AC09-96SR18500 


\section{DISCLAIMER}

This report was prepared by Washington Savannah River Company (WSRC) for the United States Department of Energy under Contract No. DE-AC09-96SR18500 and is an account of work performed under that contract. Neither the United States Department of Energy, nor WSRC, nor any of their employees makes any warranty, expressed or implied, or assumes any legal liability or responsibility for the accuracy, completeness, or usefulness, of any information, apparatus, or product or process disclosed herein or represents that its use will not infringe privately owned rights. Reference herein to any specific commercial product, process, or service by trademark, name, manufacturer or otherwise does not necessarily constitute or imply endorsement, recommendation, or favoring of same by WSRC or by the United States Government or any agency thereof. The views and opinions of the authors expressed herein do not necessarily state or reflect those of the United States Government or any agency thereof.

\section{Printed in the United States of America}

Prepared For

\section{U.S. Department of Energy}




\section{WSRC-STI-2007-00345}

Keywords: Heat Transfer Calculations, Natural Convection, CST Ion Exchange Column, RF Ion Exchange Column, Cooling Water Jacket

\section{HEAT TRANSFER ANALYSIS FOR FIXED CST AND RF COLUMNS}

Si Young Lee

October 2007

Washington Savannah River Company Savannah River National Laboratory Aiken, SC 29808

Prepared for the U.S. Department of Energy Under Contract No. DE-AC09-96SR18500 


\section{Review and Approvals}

S. Y. Lee, Author

Eng. Modeling and Simulation Group, SRNL

W. D. King, Technical Reviewer

Actinide Technology Section, SRNL

T. M. Punch, Customer Reviewer

Liquid Waste Organization

S. J. Hensel, Manager

Eng. Modeling and Simulation Group, SRNL

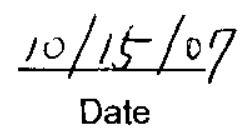

$10 / 15 / 07$

Date

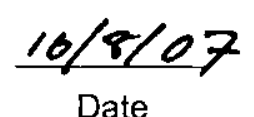

$10 / 16107$

Date 


\section{Table of Contents}

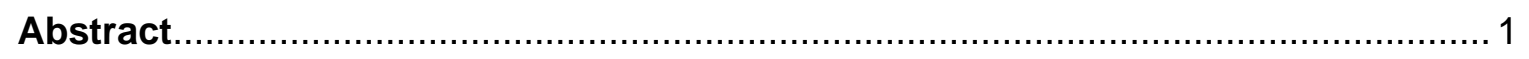

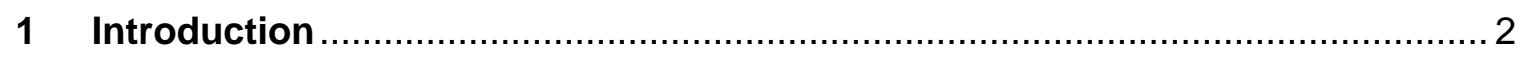

2 Approach for the Heat Transfer Analysis of the CST Bed Column .................. 2

2.1 General Governing Equations and Solution Method ................................. 7

2.2 Modeling Assumptions and Design Parameters ...................................... 14

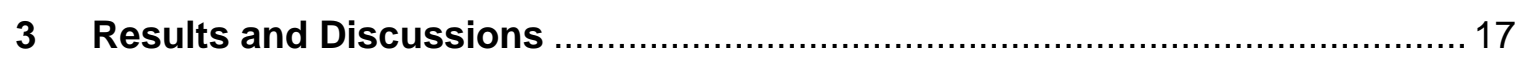

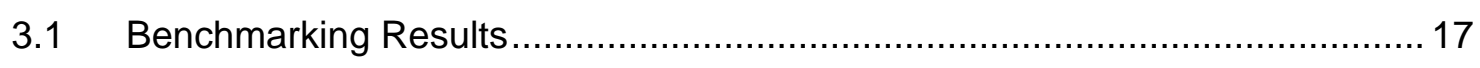

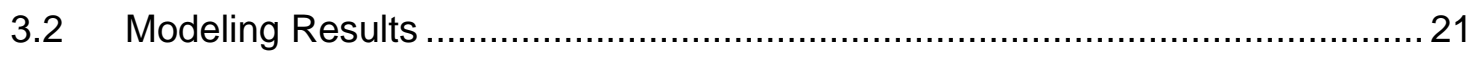

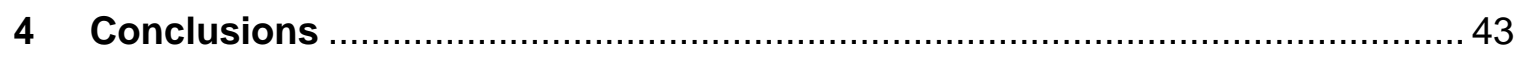

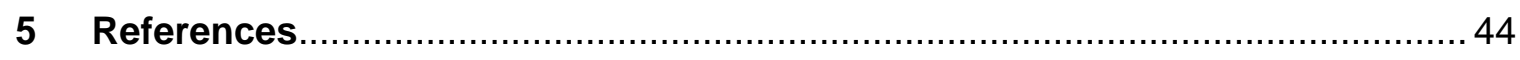


WSRC-STI-2007-00345

\section{List of Figures}

Figure 1. Typical temperature profiles of CST/RF packed bed column in energy transport process under mixed convection cooling modes.

Figure 2. Basic modeling conditions and two-dimensional computational domain boundary for the present analysis of the 28-in OD CST column with 6-in sch.

40 pipe imbedded at its center

Figure 3. Modeling geometry and basic conditions used for the heat transfer analysis... 6

Figure 4. Sensitivity results associated with numerical energy residual showing that about 11,000 meshes are established for the present analysis .................. 13

Figure 5. Computational meshes for the modeling domain

Figure 6. Natural convection heat transfer correlation available in the literature showing the conservatism imbedded in the present heat transfer analysis.

Figure 7. Forced convection correlation available in the literature demonstrating the range of the convective heat transfer through the water cooling system of the

SCIX column.

Figure 8. Graphical illustration of the heat transfer model of the Case-I CST column under natural convection cooling.

Figure 9. Comparison of steady state results between the numerical computations and theoretical results for the cylindrical column with $100 \mathrm{Ci} /$ liter heat load for model benchmarking.

Figure 10. Comparison of steady state results between the numerical computations and theoretical results for the annular-type column with $300 \mathrm{Ci} /$ liter heat load for model benchmarking.

Figure 11. Transient snapshots for CST column temperature distributions under the Case 1 model

Figure 12. Transient and steady-state temperature distributions for the bounding CST model along the line A-A' under the Case 1 model

Figure 13. Transient thermal responses of CST column containing $257 \mathrm{Ci} /$ liter radioactive heat source under the Case 1 model

Figure 14. Transient snapshots for RF column temperature distributions under the Case 1 model.

Figure 15. Transient thermal response of the fixed RF column containing $133.5 \mathrm{Ci} /$ liter radioactive heat source under the Case 1 model

Figure 16. Transient and steady-state temperature distributions for fixed RF column along the line A-A' under the Case 1 model.

Figure 17. Comparison of transient thermal responses to the CST and RF loadings for $35^{\circ} \mathrm{C}$ initial column temperature (Case 1 ).

Figure 18. Comparison of transient thermal responses of CST column containing 257 $\mathrm{Ci} /$ liter radioactive heat source between two different ambient temperatures under the Case 1 model 


\section{WSRC-STI-2007-00345}

Figure 19. Comparison of transient responses to the fixed RF column containing 133.5 $\mathrm{Ci} /$ liter radioactive heat source between two different ambient temperatures under the Case 1 model

Figure 20. Sensitivity results of different RF resin porosities under the Case 1 model containing $\mathrm{RF}$ resin materials

Figure 21. Steady-state temperature distributions for the CST column showing that maximum column temperature is $62.7^{\circ} \mathrm{C}$, and minimum temperature is $25.5^{\circ} \mathrm{C}$ under the boundary conditions of the Case 2 model

Figure 22. Steady-state temperature distributions for the fixed RF column showing that maximum column temperature is $40.7^{\circ} \mathrm{C}$, and minimum temperature is $25.3^{\circ} \mathrm{C}$ under the boundary conditions of the Case 2 model

Figure 23. Comparison of the CST columns with and without active coolant systems (Case 1 and Case 2)

Figure 24. Comparison of steady-state temperature distributions along the radial line A$A^{\prime}$ of the CST columns under combinations of active central and side jacket cooling systems 
WSRC-STI-2007-00345

\section{List of Tables}

Table 1. Baseline modeling conditions used for the present heat transfer analysis of the SCIX column.

Table 2. Material and thermal properties for heat transfer calculations of the CST and RF columns.

Table 3. Modeling conditions considered for the present coolability analysis of SCIX column under no-flow and flow conditions............................................ 12

Table 4. Heat source terms used for the present study ........................................ 17

Table 6. Transient and steady state results of maximum column temperatures for the Case-I model of 28 -in CST/RF columns cooled by natural convection boundary with $35^{\circ} \mathrm{C}$ ambient temperature.

Table 7. Comparison of the steady state temperatures for two different ambient temperatures under the Case 1 model.

Table 8. Comparison of transient durations required to reach steady state temperature distributions under the Case 1 modeling conditions ................................. 37

Table 9. Transient max. temperature results for the Case-I model under 28-in CST/RF columns cooled by natural convection boundary with two different ambient temperatures.

Table 10. Sensitivity results of the steady state temperatures for different RF resin porosities under Case 1 model.

Table 11. Sensitivity results of the transient maximum temperatures for different RF resin porosities under Case 1 model.

Table 12. Summary of steady-state results for the Case 3 model with $35^{\circ} \mathrm{C}$ ambient temperature.

Table 13. Summary of sensitivity results for the steady-state bounding models.

Table 14. Comparison of surface cooling capacities for each component of the CST column system 


\section{Abstract}

In support of a small column ion exchange (SCIX) process for the Savannah River Site waste processing program, transient and steady state two-dimensional heat transfer models have been constructed for columns loaded with cesium-saturated crystalline silicotitanate (CST) or spherical Resorcinol-Formaldehyde (RF) beads and 6 molar sodium tank waste supernate. Radiolytic decay of sorbed cesium results in heat generation within the columns. The models consider conductive heat transfer only with no convective cooling and no process flow within the columns (assumed column geometry: 27.375 in ID with a 6.625 in OD center-line cooling pipe). Heat transfer at the column walls was assumed to occur by natural convection cooling with $35^{\circ} \mathrm{C}$ air. A number of modeling calculations were performed using this computational heat transfer approach. Minimal additional calculations were also conducted to predict temperature increases expected for salt solution processed through columns of various heights at the slowest expected operational flow rate of $5 \mathrm{gpm}$. Results for the bounding model with no process flow and no active cooling indicate that the time required to reach the boiling point of $\sim 130^{\circ} \mathrm{C}$ for a CST-salt solution mixture containing $257 \mathrm{Ci} /$ liter of Cs-137 heat source (maximum expected loading for SCIX applications) at $35^{\circ} \mathrm{C}$ initial temperature is about 6 days. Modeling results for a column actively cooled with external wall jackets and the internal coolant pipe (inlet coolant water temperature: $25^{\circ} \mathrm{C}$ ) indicate that the CST column can be maintained non-boiling under these conditions indefinitely. The results also show that the maximum temperature of an RF-salt solution column containing $133 \mathrm{Ci} /$ liter of Cs-137 (maximum expected loading) will never reach boiling under any conditions (maximum predicted temperature without cooling: $88^{\circ} \mathrm{C}$ ). The results indicate that a 6 -in cooling pipe at the center of the column provides the most effective cooling mechanism for reducing the maximum temperature with either ion exchange material. Sensitivity calculations for the RF resin porosity, the ambient external column temperature, and the cooling system configuration were performed under the baseline conditions to assess the impact of these parameters on the maximum temperatures. It is noted that the cooling mechanism at the column boundary (forced versus natural convection) and the cooling system configuration significantly impact the maximum temperatures. The analysis results provide quantitative information associated with process temperature control requirements and management of the $\mathrm{SCIX}$ column. 


\section{Introduction}

High Level Waste (HLW) at the Savannah River Site is stored in three forms: sludge, saltcake, and supernate. A small column ion exchange (SCIX) process is being designed to treat dissolved saltcake waste before feeding it to the saltstone facility to be made into grout. Through this process, radioactive cesium from the salt solution is absorbed into ion exchange media (either CST or RF) which is packed within a flowthrough column. A packed column loaded with radioactive cesium generates significant heat from radiolytic decay. If engineering designs cannot handle this thermal load, hot spots may develop locally which could degrade the performance of the ion-exchange media. Performance degradation with regard to cesium removal has been observed between 50 and $80^{\circ} \mathrm{C}$ for $\mathrm{CST}[5,6]$ and at $65^{\circ} \mathrm{C}$ for RF resin [7]. In addition, the waste supernate solution will boil around $130^{\circ} \mathrm{C}$. If the columns boiled dry, the sorbent material could plug the column and lead to replacement of the entire column module. Alternatively, for organic resins such as RF there is risk of fire at elevated temperatures. The objective of the present work is to compute temperature distributions across CSTand RF-packed columns immersed in waste supernate under accident scenarios involving loss of salt solution flow through the beds and, in some cases, loss of coolant system flow. For some cases, temperature distributions were determined as a function of time after the initiation of a given accident scenario and in other cases only the final steady-state temperature distributions were calculated. In general, calculations were conducted to ensure conservative and bounding results for the maximum temperatures achievable using the current baseline column design. This information will assist in SCIX design and facility maintenance.

\section{Approach for the Heat Transfer Analysis of the Ion Exchange Column}

For the SCIX process, the baseline design involves a column bed with dimensions of 10 to $25 \mathrm{ft}$ tall and 28 in outside diameter. A fully-loaded column may contain as much as $257 \mathrm{Ci} /$ liter of Cs-137 (maximum expected loading with CST, ref. 8) based on the equilibrium cesium loading anticipated for the projected waste feed streams. This highly concentrated radioactive source will generate a significant amount of heat in the column, which corresponds to about 5 watts/gallon of volumetric heat source. Typical loadings are expected to be less than $200 \mathrm{Ci} /$ liter, which would generate about 4 watts/gallon. Under normal operating conditions, process fluid flow through the column can provide adequate heat removal from the column through a coupled conduction and convection heat transfer mechanism. However, in the case of a loss of flow accident, there are concerns about the transient thermal response rates and the maximum steady-state temperatures reached for fully-loaded columns containing each ion exchange media. Fast thermal response and high peak temperature can lead to unacceptable consequences such as media degradation and solution boiling. For computational modeling purposes, a conservative approach was taken by assuming that the primary cooling mechanisms inside and outside of the column were conduction and natural convection, respectively, and that axial heat removal from the column was negligible relative to radial heat transfer. Figure 1 illustrates the heat transfer mechanisms for the SCIX column system configurations analyzed in this report. The model was created 
using a body-fitted coordinate system and structured multi-block grids in the Computational Fluid Dynamics (CFD) preprocessing environment. A two-dimensional transient heat conduction model was developed to assess the thermal performance of the packed column with loss of flow using the prototypic geometry as shown in Fig. 2.

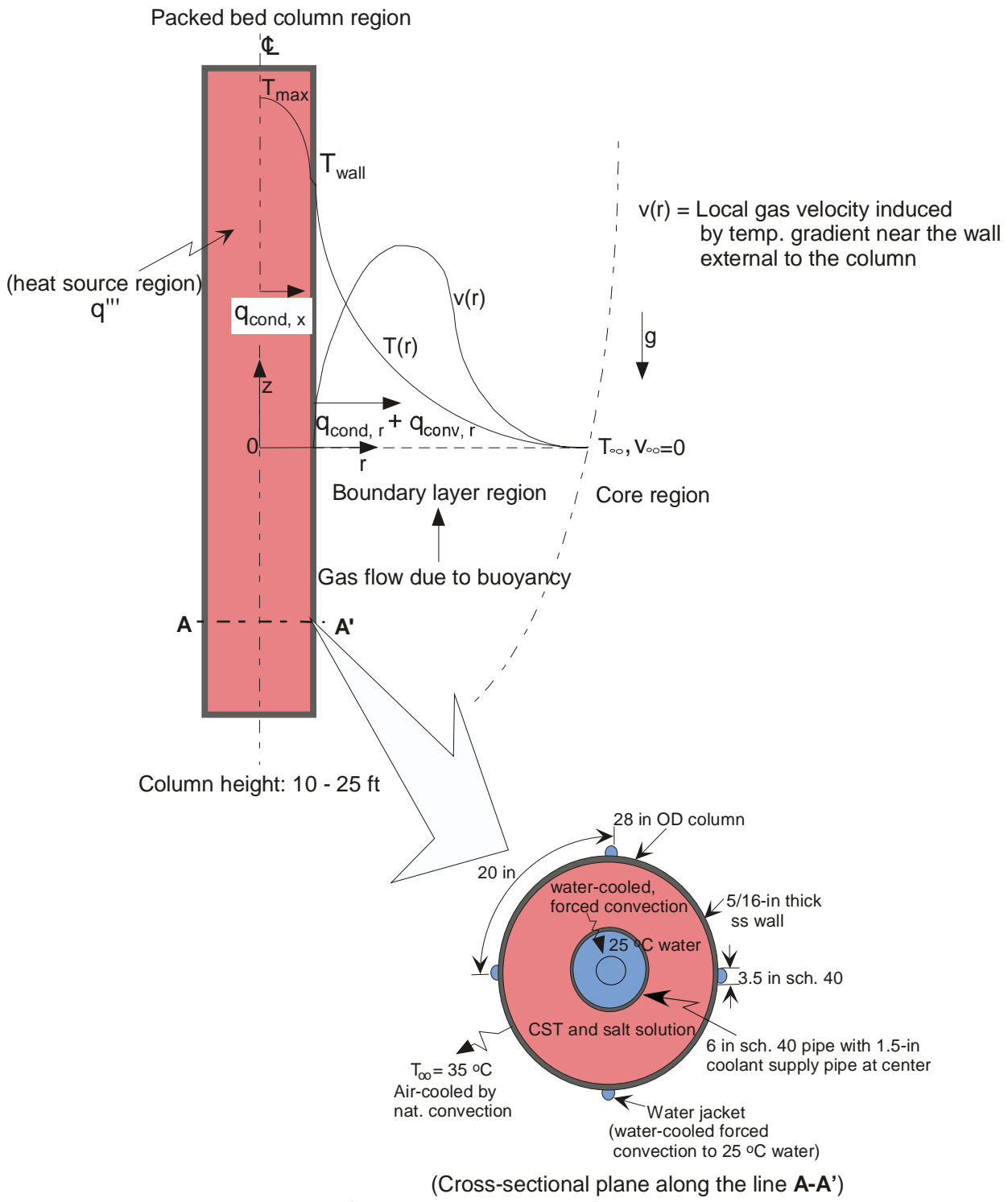

(Note: Actual wall thickness is $3 / 8$ in rather than $5 / 16$ in. This difference has a negligible impact on the results.)

Figure 1. Typical temperature profiles of packed columns under mixed convection cooling modes and no flow conditions. 


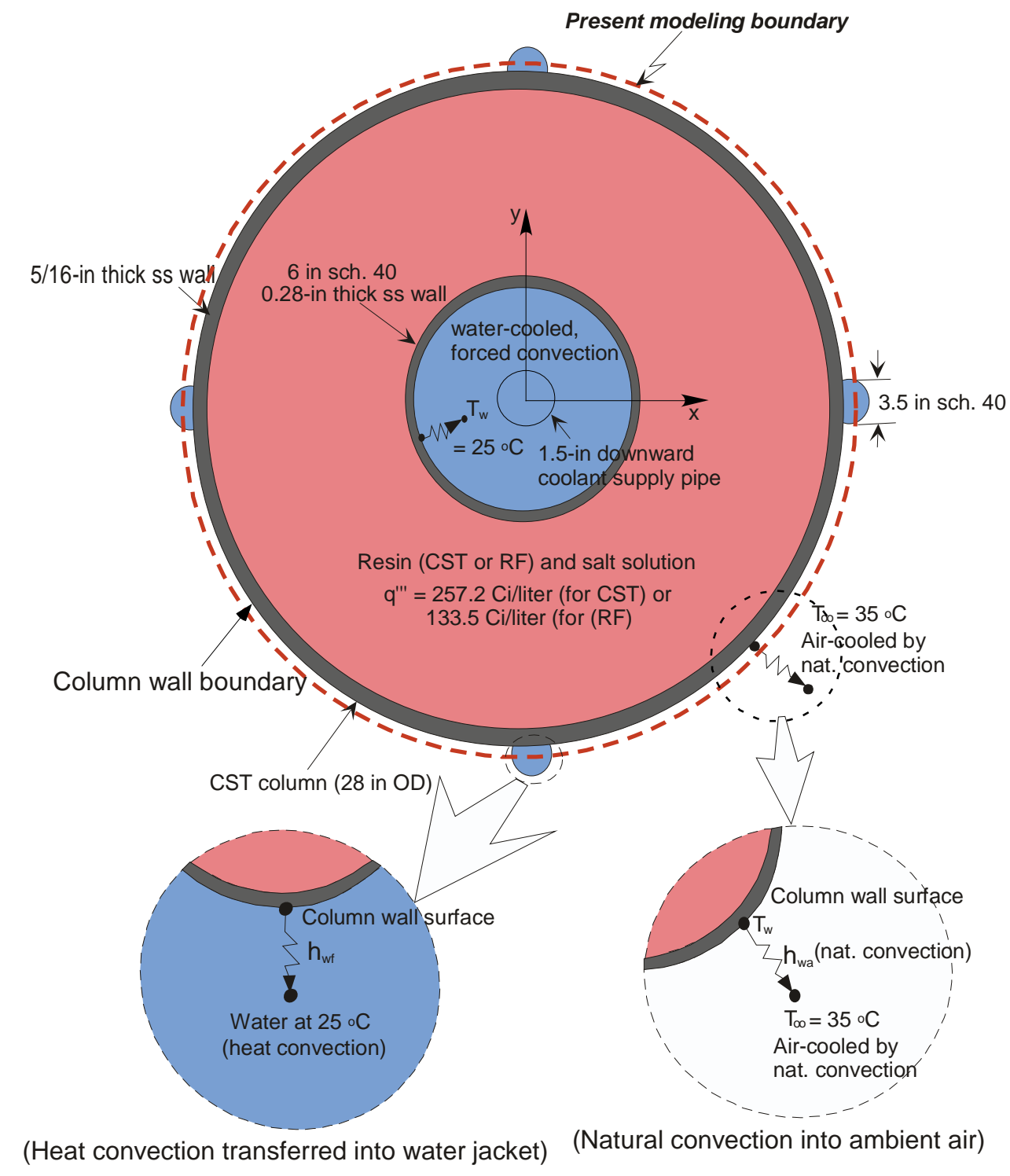

Figure 2. Basic modeling conditions and two-dimensional computational domain boundary for the present analysis of the 28-in OD column with a 6-in sch. 40 pipe imbedded at its center (annular packed bed dimensions: 27.375" OD, 6.625" ID).

The model considers three basic cases as shown Fig. 3. The first two cases are assumed to have no salt solution process flow through the bed and involve internal heat transfer by conduction only for columns filled with salt solution. Heat transfer at the walls involves natural convection from the external wall boundary to the ambient air, with the assumption that the air serves as an infinite heat sink at constant temperature. Cases 1 and 2 shown in Figure 3 are naturally-cooled stagnant columns with passive and active (convective) cooling systems, respectively. The last case, Case 3, considers the 
minimum expected salt solution flow (5 gpm) through the bed during normal operations for a bed containing the same heat source. In this case, it is assumed there is no heat loss at the column wall boundary (adiabatic boundary) and all heat transfer is through the mobile liquid phase (forced convection). Heat transfer analysis of the packed column for the basic cases is performed for a given boundary condition by using a computational heat transfer approach on a Cartesian $x-y$ grid with a commercial CFD code, Fluent ${ }^{\mathrm{TM}}$, environment.

For heat transfer analysis, the baseline modeling conditions were assumed as shown in Table 1. CST or RF resin particles were assumed to be packed inside a stainless steel cylinder that was 28 in outside diameter with a 5/16 inch thick wall. The actual baseline column design involves a $3 / 8$ in wall thickness, resulting in a 1/8 in diameter difference between the model and design conditions. This difference is believed to have a negligible impact on the modeling results. The column design is annular due to the presence of a center cooling pipe with an outside diameter of 6.625 in. Oak Ridge National Laboratory estimated the porosity of the CST packed beds to be $43.2 \%[4,5]$, and this porosity was used for both the CST and RF packed beds in this report. It is noted that discrepancies between the porosities used in this report and those used by Smith exist [8]. For CST the value of $43.2 \%$ gives more conservative results with regard to the maximum temperature than the value of $50 \%$ used by Smith. The value of $43.2 \%$ porosity for RF used in the current report is not significantly different from the value of $42 \%$ used by Smith. The void volume fraction of the packed bed impacts the material property estimations of the composite beds containing ion exchange beads and salt solution. For instance, the effective bulk density of the CST column filled with salt solution was estimated to be about $1588 \mathrm{~kg} / \mathrm{m}^{3}$ considering that the density of CST solid is $2,056 \mathrm{~kg} / \mathrm{m}^{3}$ and the total CST packed bed porosity is $57 \%$ based on fluid-solid homogenous mixture [4]. The density of the mixture was calculated as a simple weighted average of the CST and salt solution densities based on the void fraction. The bulk density for the RF-salt solution column is $1306 \mathrm{~kg} / \mathrm{m}^{3}$ based on the RF material density of $1232 \mathrm{~kg} / \mathrm{m}^{3}$ and the total packed bed porosity of $80 \%$.

The temperature distributions inside a fixed CST bed with no process flow were computed for a conservative estimation of heat load in the column. Typical natural convection conditions available in the literature and the previous analysis $[4,10]$ were used at the boundary of the modeling domain. For the modeling analysis, the column was assumed to be an infinite cylinder (the ratio of the length to diameter is larger than 4) and the heat transfer effect along the axial direction was assumed to be negligible compared to that in the radial direction. Effective composite thermal and material properties of the CST columns are obtained by using experimental values or empirical correlations available in the literature. When bulk properties of the composite bed such as density and specific heat were not available, they were estimated assuming a homogeneous distribution within the bed. For the baseline modeling conditions of the column, quasi-steady state temperature distributions were determined by taking a sequence of time steps from transient governing equations in an effort to understand how effectively the column heat is dissipated throughout the cylindrical enclosure. Specifically, this investigation includes how long it takes to reach steady state for the bounding case scenario. This information is important for operational performance assessments and for equipment designs within the ion exchange column facility. 


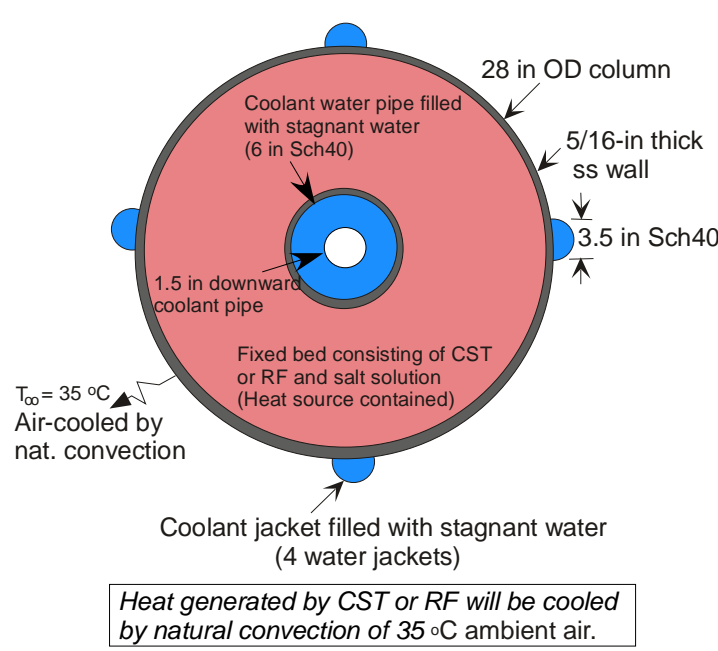

(Case 1 Model)

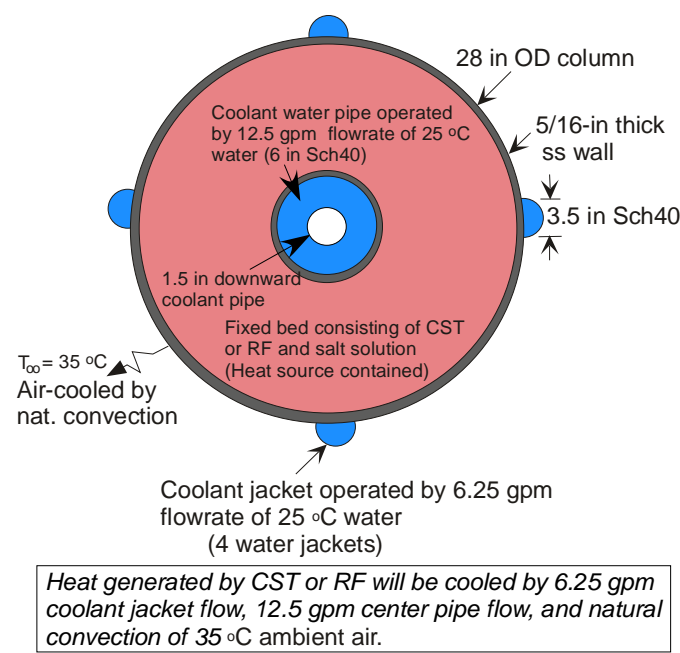

(Case 2 Model)

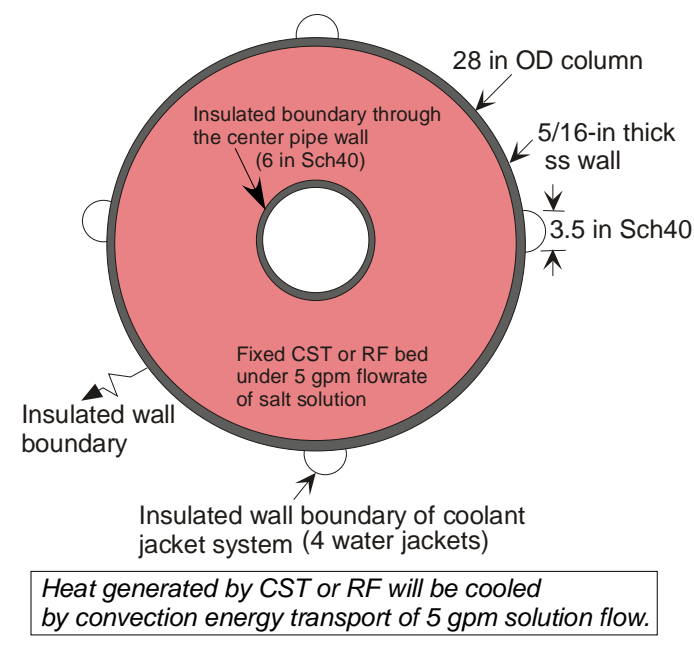

(Case 3 Model)

Figure 3. Modeling geometry and basic conditions used for the heat transfer analysis. 
Table 1. Baseline modeling conditions used for the present heat transfer analysis of the SCIX column.

\begin{tabular}{|c|c|c|}
\hline \multicolumn{2}{|c|}{ Models } & Conditions for the baseline model \\
\hline \multirow{2}{*}{$\begin{array}{l}\text { Heat load in } \\
\text { SCIX } \\
\text { column }\end{array}$} & $\begin{array}{l}\text { CST-loaded } \\
\text { column }\end{array}$ & 257.22 Ci/liter (1273.24 W/m³) [8] \\
\hline & $\begin{array}{l}\text { RF-loaded } \\
\text { column }\end{array}$ & 133.49 Ci/liter $\left(660.78 \mathrm{~W} / \mathrm{m}^{3}\right)[8]$ \\
\hline \multirow{2}{*}{$\begin{array}{l}\text { Resin } \\
\text { porosity }\end{array}$} & CST resin & $24.0 \%[8]$ \\
\hline & RF resin & $65.79 \%$ [8] (52.63\%*, 0\%*) \\
\hline \multicolumn{2}{|c|}{ Fluid inside SCIX column } & $6 \mathrm{M} \mathrm{Na}^{+}$salt solution \\
\hline \multicolumn{2}{|c|}{ Column hydraulic conditions } & no flow (Cases 1 and 2), or 5 gpm flow (Case 3) \\
\hline \multicolumn{2}{|c|}{ Granular bed conditions } & fixed bed \\
\hline \multicolumn{2}{|c|}{ Initial temperature } & $35{ }^{\circ} \mathrm{C}$ for the entire computational domain \\
\hline \multicolumn{2}{|c|}{ Ambient temperature } & $35^{\circ} \mathrm{C}\left(55^{\circ} \mathrm{C}\right)^{*}$ \\
\hline \multicolumn{2}{|c|}{$\begin{array}{l}\text { Heat transfer coefficient at } \\
\quad \text { wall, } h_{w}\left(\mathrm{~W} / \mathrm{m}^{2} \mathrm{sec}\right)\end{array}$} & $\begin{array}{l}238 \text { (for } 6 \text {-in water pipe wall), and } 620 \text { (for the column } \\
\text { wall surface attached to the water jacket), } 1.5 \mathrm{~W} / \mathrm{m}^{2} \mathrm{sec} \\
\text { (typical natural convection) [10] }]^{\star \star}\end{array}$ \\
\hline \multicolumn{2}{|c|}{$\begin{array}{l}\text { Coolant water flowrate in } \\
\text { cooling jackets }\end{array}$} & $\begin{array}{c}6.25 \mathrm{gpm} \text { each side jacket, } 12.5 \text { for annular central } \\
\text { coolant pipe }\end{array}$ \\
\hline \multicolumn{2}{|c|}{ Coolant water temperature } & no forced circulation or $25^{\circ} \mathrm{C}^{\star}$ fixed by forced circulation \\
\hline \multicolumn{2}{|c|}{ Bed porosity } & $43.2 \%[4,5]$ \\
\hline
\end{tabular}

Note: " all Curies assumed converted to heat load wattage

*Conditions to be evaluated by sensitivity analysis

** Heat transfer coefficient at the exterior wall of the CST column

\subsection{General Governing Equations and Solution Method}

The CST column system contains a thin layer of stainless steel wall material surrounding the CST or RF resin particles packed inside the column container with The void space filled with salt solution. Potential cooling mechanisms of the column system are shown in Fig. 1 [3]. The column designs considered for the present work are shown in Fig. 3. Thermal and material properties for the packed materials and the column wall were obtained from the literature $[4-7,10,11]$. 
The heat generated by the packed column with no process flow will be transferred by conduction through a multi-layered medium and eventually will be transported to the ambient room through the physical processes of conduction and convection heat transport. In order to ensure conservatism, natural convection heat transfer within the packed beds is neglected. The heat transfer rate at the solid-fluid interface boundary is computed using the fluid temperature gradient and heat transfer coefficient at the solid wall boundary with given ambient temperature. For the present work, the heat transfer coefficient will be estimated by the literature correlation $[14,16]$.

When cooled by natural convection, the fluid temperature gradient in the column depends on the external gas flow field that is driven by the density gradient at the wall boundary layer and is dependent on the rate at which the gas fluid convects the heat away. Typical air flow and temperature profiles within the system under actual energy transport processes, including buoyancy-driven natural convection due to the fluid temperature gradient, are illustrated in Fig. 1. Temperature decreases rapidly due to the convective cooling effect within a boundary layer region. The boundary layer flow is a buoyancy-induced motion, resulting from body forces acting on masses, which arise from temperature gradients in the fluid. It is virtually impossible to observe pure heat conduction in a gas medium because as soon as a temperature difference is imposed on a fluid, natural convection currents will occur as a result of force imbalances caused by density differences. Thus energy transport is coupled to the momentum transport through the wall interface of the solid and fluid regions, but in this case, the ambient temperature and the heat transfer coefficient at the solid wall will be assumed to be constant. This will lead to the reduction of computational time. In the previous work [4], sensitivity runs were performed to estimate conservatism imbedded in the assumptions.

The two-dimensional governing equations for the present analysis in the Cartesian coordinate system are shown below. For a general energy balance equation on a control segment of the column system with volumetric heat source q"',

$\rho \frac{\partial h}{\partial t}-\frac{\partial}{\partial x}\left\{k \frac{\partial T}{\partial x}\right\}-\frac{\partial}{\partial y}\left\{k \frac{\partial T}{\partial y}\right\}-q^{\prime \prime \prime}=0$

where $\mathrm{h}$ is enthalpy. The heat source term is included in the present model since a significant amount of decay heat is generated from the ion exchange process through the column packed with CST or RF resin.

In eq. (1), energy terms within a control volume of a solid medium in the column include conduction $(k \nabla T)$ and energy storage due to transients $\left(\rho \not h / \partial=\rho C_{p} \partial T / \partial t\right)$. In this situation, radiation and convection terms in the energy balance equation were neglected. $k$ in eq. (1) is thermal conductivity of the medium in the computational domain. This property value will be provided by the constitutive relation later. The packed column with volumetric heat source q"' will be cooled down by a natural convection process through its wall surface as shown in Fig. 2. In this case, when wall boundary and initial conditions are provided, the governing equations are complete. They are

$-(k \nabla T)_{\text {wall }}=h_{w}\left(T-T_{\infty}\right)_{\text {wall }}$

and

$T(t=0)=T_{i}$ 
In eq. (2), $h_{w}$ and $T_{\infty}$ are wall heat transfer coefficient and ambient temperature, respectively. $T_{i}$ in eq. (3) is initial temperature of the computational domain.

The heat transfer coefficient at the outside wall of the column $\left(h_{w}\right)$ is obtained by using the empirical correlation available in the literature. As the baseline modeling conditions of Case 1 and 2, the column is assumed to be cooled by the natural convection. In this situation, the natural convection flow regime for the air-cooled design should be estimated based on the non-dimensional Grashof number $\left(\mathrm{Gr}_{\mathrm{L}}\right)$, which is the parameter describing the ratio of buoyancy to viscous forces for a vertically-oriented cylinder with height $L$. The Grashof number performs much the same function for natural convection flow as the Reynolds $(\mathrm{Re})$ number does for forced convection. Under normal conditions one may expect that the laminar-to-turbulent transition will take place at about $G r_{L} \approx 10^{9}$.

For a typical air-cooled system without forced air circulation,

$G r_{L}=\frac{g \beta L^{3}\left(T_{w}-T_{\infty}\right)}{v_{f}^{2}}$

where $L=$ characteristic length parameter $(=3.048 \mathrm{~m})$,

$$
\begin{aligned}
& \beta=\text { thermal expansion coefficient }\left(=3.34 \times 10^{-3} \mathrm{~K}^{-1}\right), \\
& v_{f}=\left(\mu_{f} / \rho_{f}\right)=\text { kinematic fluid viscosity }\left(=1.60 \times 10^{-5} \mathrm{~m}^{2} / \mathrm{sec}\right) .
\end{aligned}
$$

In eq. (4), the Grashof number was estimated as about $2 \times 10^{10}$ for a $5^{\circ} \mathrm{C}$ temperature difference at the wall in order to examine the boundary layer flow regime of natural convection. This corresponds to the turbulent flow according to the literature [13].

For the present analysis, the natural convection regime around the column is assumed to be turbulent. As shown in Fig. 1, geometrical configurations for the present analysis involving a vertically-oriented cylindrical column. However, literature results [14] show that when the geometrical ratio of the diameter $(D)$ to the height $(L)$ is greater than or equal to $35\left(G r_{L}\right)^{-0.25}$, the natural convection correlation for vertical flat-plates can be applied to the vertical cylinder equally. For the present configurations of the 28-in column,

$\left(\frac{D}{L}\right)_{\text {min. }}=0.093 \geq\left(35 G r_{L}^{-0.25}\right) \approx 0.09$

Warner and Arpaci [16] performed an experimental investigation of turbulent natural convection in air from a vertical heated plate. The results of this study showed good agreement with the following correlation for Grashof number up to $10^{12}$ :

$$
N u_{L}=\left(\frac{h_{w} L}{k_{f}}\right)=0.10\left(P r_{f} G r_{L}\right)^{1 / 3}
$$

where $\operatorname{Pr}_{f}$ is Prandtl number and

$$
\operatorname{Pr}_{f}=\frac{\mu_{f} C p_{f}}{k_{f}} \text {. }
$$


In eq. (6) all material properties should be evaluated at the mean fluid temperature of $T_{f}=0.5\left(T_{w}+T_{\infty}\right)$, and $h_{w}$ is natural convection heat transfer coefficient at the heated solid wall. $k_{f}$ is thermal conductivity of fluid at the fluid temperature $T_{f}$.

These governing equations are applied to the two-dimensional computation domain depending on the physical model for the heat transfer analysis of the CST (or RF) column assuming that the axial heat transfer of the column is negligible. There is heat source information (q"' in eq. (1)) for the column region. For conservative heat transfer calculations, the heat source was estimated for a fully-loaded and uniformly-distributed bed packed with CST or RF solid material. The current calculations used two heat loads, $257.22 \mathrm{Ci} /$ liter for CST and 133.49 for RF resin, corresponding to 1273 and 661 $\mathrm{W} / \mathrm{m}^{3}$, respectively, as volumetric heat source q"' in the energy equation as shown in Table 1. Total powers generated by the CST and RF columns were obtained by multiplying the volumetric source by total column volume for each of the three different column heights $(10,15,25 \mathrm{ft})$. This information was based on the previous modeling results [12]. In addition, this region was included as a conduction zone and was assumed as constant thermal conductivity instead of considering temperaturedependency for the energy equation since the thermal conductivity of the material increases linearly with temperature. Effective thermal conductivity of the CST-salt column was used from the experimental correlation developed by ORNL [5]. Thermal properties of phenolic plastic material [20], which is similar to RF resin, were used for the evaluation of effective thermal conductivity for the RF-salt column since no known measurements of the thermal properties of spherical RF resin have been reported. Phenolic plastic polymer is expected to have similar thermal properties to resorcinol formaldehyde polymer due to similarities in chemical structure for these materials. Organic polymers are not expected to exhibit large variabilities with regard to thermal conductivity within a given chemical family.

The material and thermal properties for the components of the CST- or RF-packed column system are provided in Table 2. Using these thermal properties, a twodimensional transient conduction model was performed to predict transient thermal responses of the fixed bed region in case of the loss of the salt process flow. For computational efficiency, effective thermal conductivity for the composite column region was used. Effective thermal conductivity of the bed region was estimated by the literature correlation [18]. That is, effective thermal conductivity of the bed $\left(k_{b, e f f}\right)$ was estimated by the previous work [4].

Effective material properties of the CST or RF column filled with salt solution are computed in terms of the total porosity of the packed column bed $\varepsilon$. Effective density $\rho_{b \text {,eff }}$ and specific heat $C p_{b, \text { eff }}$ of the bed column are based on a homogeneous assumption. That is,

$$
\begin{aligned}
& \rho_{b, \text { eff }}=\varepsilon \rho_{f}+(1-\varepsilon) \rho_{p} \\
& C p_{b, \text { eff }}=\varepsilon C p_{f}+(1-\varepsilon) C p_{p}
\end{aligned}
$$

In eqs. (8) and (9), subscripts $f$ and $p$ refer to the fluid and particle materials within the packed bed, respectively. Thus, computational time can be reduced by modeling a single-material region with the effective thermal conductivity instead of modeling a multimaterial region composed of two different materials. This leads to a reduction in the computational time and effort with reasonable accuracy. 
The two-dimensional geometry file was created using the multi-block preprocessor of the Fluent $^{\mathrm{TM}}$ code [9] under the body-fitted coordinate system, which allows the treatment of non-orthogonal geometries. The present model consists of 5 element blocks and 2 different material zones on the $x$-y computational plane. Non-uniform two-dimensional structured meshes of the computational domain were used to capture the smooth temperature gradient across the boundary zone of the two different material regions. Typical modeling boundaries for the cases considered here are shown in Table 3. Numerical solution techniques to solve the governing equations were described in Reference $[4,10]$.

The overall energy balance should be checked to demonstrate the adequacy of the grid fineness used. This was done by using eq. (10).

$$
R=-\int_{A_{W}} q_{W}^{\prime \prime} d A+q " V_{F}
$$

The volumetric heat source term, q"', in eq. (10) is given by the code input. For all the cases considered here, energy residual $(R)$ is less than about 0.5 watt. For instance, the residual results for the Case 1 model of the CST-salt solution bed are shown as function of grid number in Fig. 4. For the present analysis, an optimum grid of about 11,000 cells has been established from the grid sensitivity analysis under the Linux HP DL585 platform. Nonuniform two-dimensional meshes used for the computational analysis of the Case 1 and Case 2 columns are shown in Fig. 5.

Table 2. Material and thermal properties for heat transfer calculations of the CST and RF columns

\begin{tabular}{|c|c|c|c|c|}
\hline \multicolumn{2}{|c|}{ Material } & $\begin{array}{c}\text { Thermal conductivity } \\
(\mathrm{W} / \mathrm{mK})\end{array}$ & $\begin{array}{c}\text { Density } \\
(\mathrm{kg} / \mathrm{m} 3)\end{array}$ & $\begin{array}{c}\text { Specific heat } \\
(\mathrm{J} / \mathrm{kgK})\end{array}$ \\
\hline $\begin{array}{c}\text { Ion } \\
\text { exchange } \\
\text { resin }\end{array}$ & CST & 0.1617 & $2056.3^{* *}$ & 1052.3 \\
\cline { 2 - 5 } & $\mathrm{RF}^{*}$ & 0.2770 & $1615.0^{* *}$ & 1109.5 \\
\hline Salt Solution [8] & 0.68 & 1232.0 & 3630.0 \\
\hline CST-Salt Solution & $0.4125^{\#}$ & $\begin{array}{c}1587.8^{\#} \\
\text { (from eqn. 8) }\end{array}$ & $\begin{array}{c}2517.3^{\#} \\
\text { (from eqn. 9) }\end{array}$ \\
\hline RF-Salt Solution & $0.5987^{\#}$ & $\begin{array}{c}1306.4^{\#} \\
\text { (from eqn. 8) }\end{array}$ & $\begin{array}{c}3140.2^{\#} \\
\text { (from eqn. 9) }\end{array}$ \\
\hline Stainless steel [20] & 17.30 & 7800.0 & 486.0 \\
\hline
\end{tabular}

Note: \# based on non-linear empirical correlation of Krupiczka at $25{ }^{\circ} \mathrm{C}$ [18] considering particle porosities $\left(\varepsilon_{\mathrm{CST} \text {, particle }}=24 \%, \varepsilon_{\mathrm{RF} \text {, particle }}=65.79 \%\right)$ and the volume fractions of air or fluid in the packed beds ( 0.432 for both CST and RF), giving total bed porosities of 0.57 and 0.80 for CST and RF, respectively (total porosity evaluated considering bead and bed porosity.)

* based on Phenolic plastic material similar to RF [22]

** based on material density (not bulk density) 
Table 3. Modeling conditions considered for the present coolability analysis of SCIX column under no-flow and flow conditions.

\begin{tabular}{|c|c|c|c|c|}
\hline \multirow{3}{*}{\multicolumn{2}{|c|}{ Parameters }} & \multicolumn{3}{|c|}{ Modeling cases } \\
\hline & & \multicolumn{2}{|c|}{ Bounding Model } & \multirow{2}{*}{$\begin{array}{c}\text { Nominal Model } \\
\text { Case } 3\end{array}$} \\
\hline & & Case 1 & Case 2 & \\
\hline \multicolumn{2}{|c|}{ Max. heat loads (Ci/liter) } & \multicolumn{3}{|c|}{ CST: 257.22} \\
\hline \multirow{3}{*}{$\begin{array}{c}\text { Max. total } \\
\text { heat source } \\
\text { generated by } \\
\text { CST/RF resin }\end{array}$} & $10 \mathrm{ft}$ high & \multicolumn{3}{|c|}{1387.2 watts for CST, 719.9 watts for RF } \\
\hline & $15 \mathrm{ft}$ high & \multicolumn{3}{|c|}{2080.8 watts for CST, 1079.9 watts for RF } \\
\hline & $25 \mathrm{ft}$ high & \multicolumn{3}{|c|}{3468.0 watts for CST, 1799.8 watts for RF } \\
\hline \multicolumn{2}{|c|}{$\begin{array}{c}\text { Salt Solution Flow } \\
\text { through Bed (Cooling } \\
\text { mechanism) }\end{array}$} & $\begin{array}{l}\text { No flow } \\
\text { (Conduction) }\end{array}$ & $\begin{array}{l}\text { No flow } \\
\text { (Conduction) }\end{array}$ & $\begin{array}{l}5 \mathrm{gpm} \\
\text { (Convection) }\end{array}$ \\
\hline \multicolumn{2}{|c|}{$\begin{array}{l}\text { Operating conditions of } \\
\text { central coolant pipe and } \\
\text { four water jackets at the } \\
\text { column wall boundary }\end{array}$} & $\begin{array}{l}\text { No flow } \\
\text { (conduction) }\end{array}$ & $\begin{array}{l}6.25 \text { gpm each side } \\
\text { jacket, } 12.5 \text { gpm for } \\
\text { annular central } \\
\text { coolant pipe } \\
\text { (forced convection) }\end{array}$ & $\begin{array}{l}\text { No heat transfer } \\
\text { through walls } \\
\text { (insulation } \\
\text { boundary) }\end{array}$ \\
\hline \multicolumn{2}{|c|}{$\begin{array}{l}\text { Basic cooling mechanism } \\
\text { at column boundary }\end{array}$} & $\begin{array}{l}\text { Natural convection } \\
\text { cooled by air }\end{array}$ & Mixed convection* & $\begin{array}{l}\text { Convective heat } \\
\text { transport with } \\
\text { insulated boundary } \\
\text { at column wall }\end{array}$ \\
\hline \multicolumn{2}{|c|}{$\begin{array}{c}\text { Tank headspace } \\
\text { temperature } \\
\text { (no forced air circulation, } \\
\text { no column liquid } \\
\text { immersion) }\end{array}$} & $35^{\circ} \mathrm{C}$ & $35^{\circ} \mathrm{C}$ & $35^{\circ} \mathrm{C}$ \\
\hline \multicolumn{2}{|c|}{ Modeling mode } & $\begin{array}{l}\text { Transient and } \\
\text { steady-state } \\
\text { (35 }{ }^{\circ} \mathrm{C} \text { initial salt } \\
\text { solution and bed } \\
\text { temperature) }\end{array}$ & Steady-state & Steady-state \\
\hline
\end{tabular}

Note: * Natural heat transfer coefficient at the exterior wall of the SCIX column, and forced convection $\left(\mathrm{h}_{\mathrm{wf}}\right)$ for water jacket wall and central pipe surface evaluated by Dittus-Boelter correlation, eq. (12) 


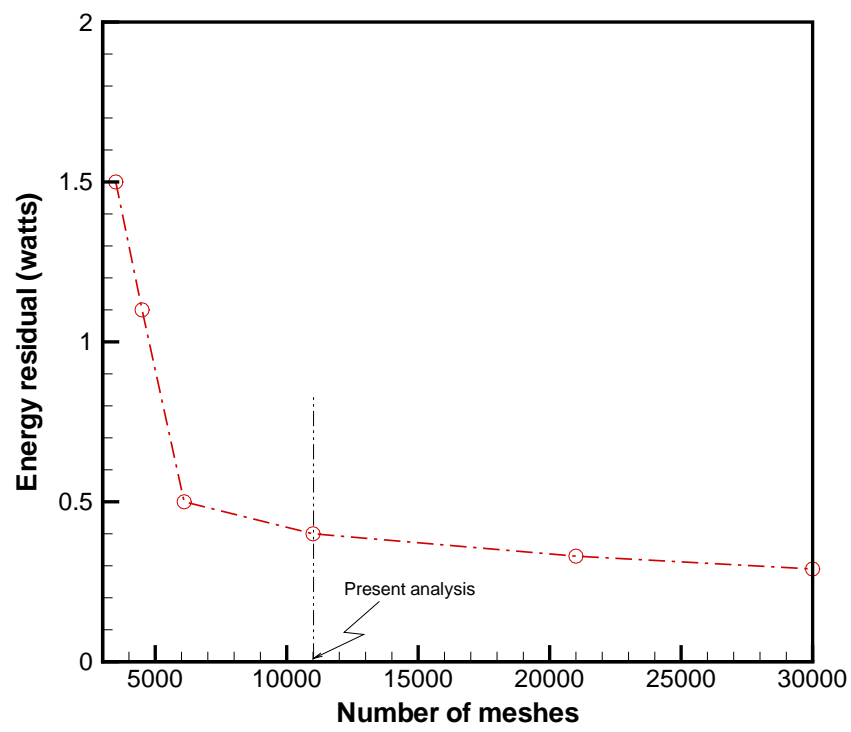

Figure 4. Sensitivity results associated with numerical energy residual showing that about 11,000 meshes are established for the present analysis

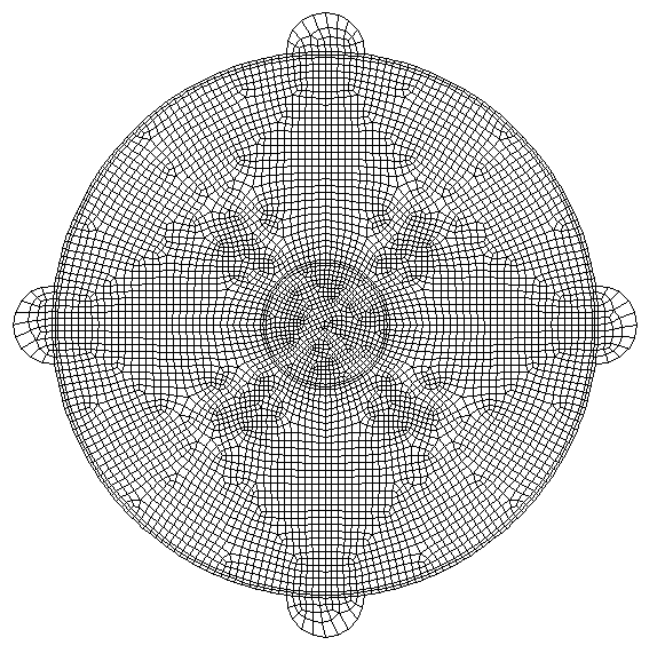

Figure 5. Computational meshes for the modeling domain 


\subsection{Modeling Assumptions and Design Parameters}

The present analyses are made for the heat transfer calculations of CST and RF ion exchange columns. The computational modeling domain is shown in Fig. 2. A conservative approach was taken to estimate transient temperature profiles of fullyloaded columns with no process fluid flow. In this situation, the column with heat source was assumed to be cooled only by a typical natural convection mechanism at the column wall, although convection within the bed was neglected.

The present computations used the following main assumptions:

- Column is filled with a fixed bed of CST or RF particles and salt solution (no convective fluid flow in bed).

- Column ambient temperature is constant $\left(35^{\circ} \mathrm{C}\right.$ or $\left.55^{\circ} \mathrm{C}\right)$.

- Columns are assumed to be filled with one of two no-flow scenarios. One column consists of CST and salt solution (CST-salt solution), and the other is the column filled with RF and salt solution (RF-salt solution). Both columns have $35^{\circ} \mathrm{C}$ initial temperatures for the purpose of transient system evaluations.

- Outside the column there is no forced convective airflow, so natural convection is the primary heat transfer mechanism from the exterior of the CST column wall. Radiative cooling contributions at the inner and outer wall surfaces of the column are conservatively assumed to be negligible.

- The heat source $\left({ }^{137} \mathrm{Cs}\right.$ and ${ }^{137 \mathrm{~m}} \mathrm{Ba}$ decay) is uniformly distributed throughout the entire packed column and produces 1.273 watts/liter assuming that the column is loaded to $257 \mathrm{Ci} /$ liter in the case of CST packing material. The RF column produces 0.66 watts/liter due to $133.5 \mathrm{Ci} /$ liter decay source.

A typical natural convective heat transfer coefficient $\left(h_{w}\right)$ of $1.5 \mathrm{~W} / \mathrm{m}^{2} \mathrm{~K}$ was used as an external wall boundary condition from the previous works $[4,8,10,17]$. The present value of the heat transfer coefficient can be justified on the following basis:

For a conservative calculation, a low temperature gradient at the wall boundary layer was used to estimate natural convection capability for the present geometrical configurations. Heat transfer coefficient $\left(h_{w}\right)$ for natural convective cooling under a turbulent flow regime $\left(\mathrm{Ra}_{f}=\operatorname{Gr}_{L} \operatorname{Pr}_{f}>10^{9}\right)$ is given in terms of non-dimensional numbers empirically.

$$
N u_{L}=\frac{h_{w} L}{k_{w}}=C\left(G r_{L} \operatorname{Pr}_{f}\right)^{m} \quad \text { for } \operatorname{Gr}_{L} \operatorname{Pr}_{f}<10^{12}
$$

where $\mathrm{C}$ and $\mathrm{m}$ are the coefficients determined from literature data and $L$ is the characteristic length of the CST column.

For the present geometrical configuration, $\mathrm{C}=0.10$ and $\mathrm{m}=0.333$ are given by Warner and Arpaci using the experimental data [16]. From eq. (11), the heat transfer coefficient $\left(h_{w}\right)$ is about $1.5 \mathrm{~W} / \mathrm{m}^{2} \mathrm{~K}$ corresponding to $N u_{L} \approx 169$ conservatively under the present conditions. Figure 6 shows the quantified results for the literature correlation based on turbulent natural convection, which was developed by Warner and Aparci. The figure shows the conservatism imbedded in the present modeling conditions for the natural convection through the wall surface of the CST column containing the decay heat 
source. In the previous work [17], wall heat transfer driven by natural convection was evaluated using boundary layer theory.

Heat transfer coefficients $\left(h_{w f}\right)$ for forced convective heat transfer mechanisms through the column wall attached to the water jackets and through the inner surface of the coolant pipe at the column center were estimated by Dittus-Boelter's correlation [21]. That is,

$N u_{d}=\frac{h_{w f} d_{h}}{k_{w f}}=0.023\left(R e_{d}\right)^{0.8}\left(P r_{w f}\right)^{a}$ for $R e_{d}>2000$

Equation (12) is applicable to turbulent flow when the Reynolds number is larger than 2,000 in terms of the hydraulic diameter, and the parameter a in eq. (12) is 0.4 when the fluid is heated as modeled in the present work. The Reynolds number for the present study is about 7,000 when $6.25 \mathrm{gpm}$ flowrate of water flows through the 3.5 -in half-moon coolant tubes, which corresponds to $0.25 \mathrm{~m} / \mathrm{sec}$ flow velocity. In the present work, one of two bounding cases, Case 2, includes a forced convection mechanism as shown in Table 3. Forced convection heat transfer coefficients at the water jackets $\left(h_{w f}\right)$ attached to the exterior of the column wall and at the inner surface of 6-in water pipe were estimated by eq. (12). From the baseline modeling condition, the wall heat transfer coefficient governed by a forced convection mechanism was estimated as $h_{w f}=238$ $\left(\mathrm{W} / \mathrm{m}^{2} \mathrm{~K}\right)$ for the wall surface of the 6 -in central coolant pipe and $h_{w f}=620\left(\mathrm{~W} / \mathrm{m}^{2} \mathrm{~K}\right)$ for the wall of 3.5-in water jacket. Figure 7 shows quantified results for the present modeling conditions in terms of Reynolds number.

The main design parameters involved for the heat transfer in a fixed bed SCIX column are as follows:

- Ambient air temperature around the column system

- Heat load of the CST or RF resin column

- External and internal heat removal capability of the column such as coolant pipe size and flow conditions

Table 3 presents the modeling boundary conditions for the base cases of the present column loaded with CST or RF resin. Table 4 shows a range of total heat loads generated by the Cs absorption from salt solution into the CST and RF resin materials during normal operation of the SCIX column. These heat loads will be used as heat source term q"' in eq. (1) for the modeling calculations. 


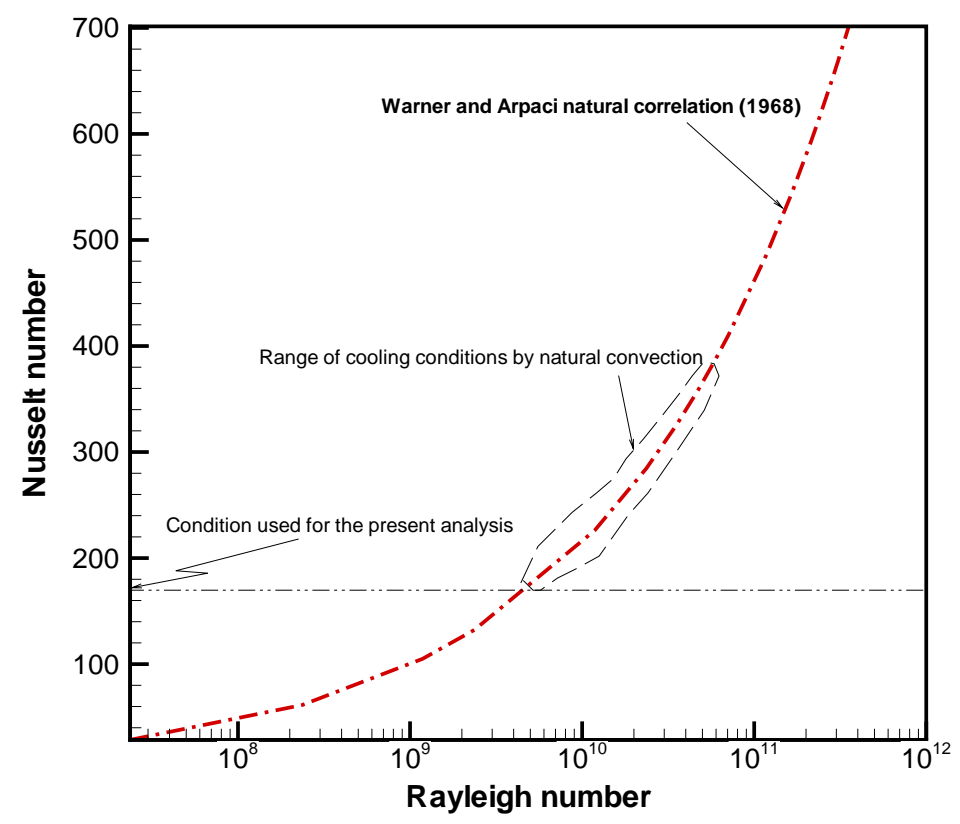

Figure 6. Natural convection heat transfer correlation available in the literature showing the conservatism imbedded in the present heat transfer analysis.

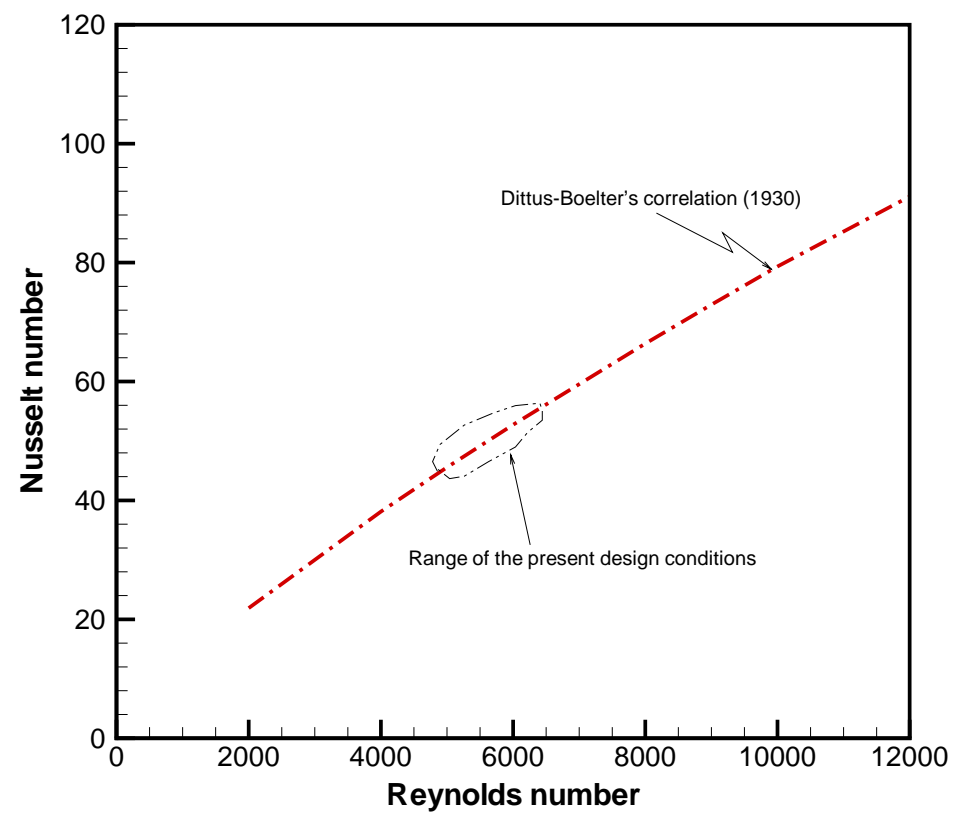

Figure 7. Forced convection correlation available in the literature demonstrating the range of the convective heat transfer through the water cooling system of the SCIX column. 
Table 4. Heat source terms used for the present study

\begin{tabular}{|c|c|c|c|c|c|}
\hline \multirow{2}{*}{$\begin{array}{c}\text { Column } \\
\text { height } \\
\text { (ft) }\end{array}$} & \multicolumn{2}{|c|}{$\begin{array}{c}\text { Decay heat source } \\
\text { (Ci/liter) }\end{array}$} & \multirow{2}{*}{$\begin{array}{c}\text { Total column } \\
\text { volume } \\
\text { (liters) }\end{array}$} & \multicolumn{2}{|c|}{$\begin{array}{c}\text { Total maximum heat sources } \\
\text { generated by column loading } \\
\text { (watts)* }\end{array}$} \\
\cline { 6 - 7 } & CST & RF & & CST & RF \\
\hline 10 & 257.22 & 133.49 & 1089.5 & 1387.20 & 719.92 \\
\hline 15 & 257.22 & 133.49 & 1634.3 & 2080.80 & 1079.88 \\
\hline 25 & 257.22 & 133.49 & 2723.8 & 3468.00 & 1799.79 \\
\hline
\end{tabular}

Note: ${ }^{\star}$ Conversion factor for Cs-137 decay heat is 0.00495 watts/Ci.

\section{$3 \quad$ Results and Discussions}

A two-dimensional modeling approach has been taken to compute temperature distributions within the modeling domain shown in Fig. 2 and to investigate transient temperature responses to decay heat loads for CST- and RF-packed columns with no process flow. For modeling Cases 1 and 2, these columns are assumed to be cooled primarily by natural and forced convection at the walls, respectively. For Case 3, process flow through the column at $5 \mathrm{gpm}$ under adiabatic wall boundary conditions was considered to quantify nominal convective cooling effects. The three cases are illustrated in Fig. 3 and their modeling conditions are summarized in Table 3.

\subsection{Benchmarking Results}

A theoretical approach for steady-state conduction heat transfer of a multi-layered cylinder containing a heat generation source was taken to verify the present computational model under the geometrical and physical conditions shown in Fig. 8 for a CST-packed column without a central cooling tube. These evaluations were conducted to benchmark and validate the heat transfer model. The theoretical model was based on a one-dimensional approach. Under steady-state conditions, the energy equation (1) for the CST packed column with effective thermal conductivity $k_{b, \text { eff }}$ becomes

$k_{b, \text { eff }} \nabla^{2} T+q^{\prime \prime \prime}=0$

For the CST column region with a uniformly distributed heat generation source q"' as shown in Fig. 8, eq. (13) becomes

$\frac{d^{2} T}{d r^{2}}+\frac{1}{r} \frac{d T}{d r}+\frac{q^{\prime \prime \prime}}{k_{b, \text { eff }}}=0$

As boundary conditions, the following relations at the center and wall of the CST column are applied to the above equation, eq. (14).

$\left.\frac{d T}{d r}\right|_{r=0}=0$ 
$T(r=R)=T_{s}$

After integrating eq. (14) and applying the boundary conditions, the radial temperature distribution for the CST column region with heat generation source q"' becomes

$T(r)=T_{s}+\frac{q^{\prime \prime \prime}}{4 k_{b, \text { eff }}}\left(R^{2}-r^{2}\right) \quad(0 \leq r \leq R)$

Equations governing the stainless wall region $(R \leq r \leq(R+d))$ with no heat source $\left(q^{\prime \prime \prime}=0\right)$ are

$\frac{d^{2} T}{d r^{2}}+\frac{1}{r} \frac{d T}{d r}=0$

Boundary conditions at the wall of the column are

$T(r=(R+d))=T_{w}$

and

$q_{w}^{\prime \prime}=-\left.k_{w} \frac{d T}{d r}\right|_{r=(R+d)}=h_{w}\left(T_{w}-T_{\infty}\right)$.

where $\mathrm{d}$ is the stainless steel wall thickness of the CST column, and $k_{w}$ is thermal conductivity of stainless steel wall.

In eq. (20) the wall heat flux $\left(q_{w}^{\prime \prime}\right)$ can be obtained by the energy balance between the heat source and the heat sink when the volumetric heat source q"' is spatially uniform in Region-I of Fig. 8. The resulting equation for the wall heat flux is

$$
q_{w}^{\prime \prime}=q^{\prime \prime \prime}\left(\frac{V_{b}}{A_{w}}\right)=q^{\prime \prime \prime}\left\{\frac{\pi R^{2} L}{2 \pi(R+d) L}\right\}=q^{\prime \prime \prime}\left\{\frac{R^{2}}{2(R+d)}\right\}
$$

Using eqs. (19), (20), and (21), the radial temperature distribution of the CST wall region with no heat source $(q " '=0)$ becomes

$$
\begin{array}{rlrl}
T(r) & =T_{w}+\frac{q_{w}^{\prime \prime}(R+d)}{k_{w}} \ln \left(\frac{R+d}{r}\right) & \\
& =T_{w}+\frac{q^{\prime \prime \prime} R^{2}}{2 k_{w}} \ln \left(\frac{R+d}{r}\right) \quad(R \leq r \leq(R+d))
\end{array}
$$

The surface temperature can be evaluated by eq. (22). That is,

$$
T_{s}=T_{w}+\frac{q^{\prime \prime \prime} R^{2}}{2 k_{w}} \ln \left(\frac{R+d}{R}\right)
$$




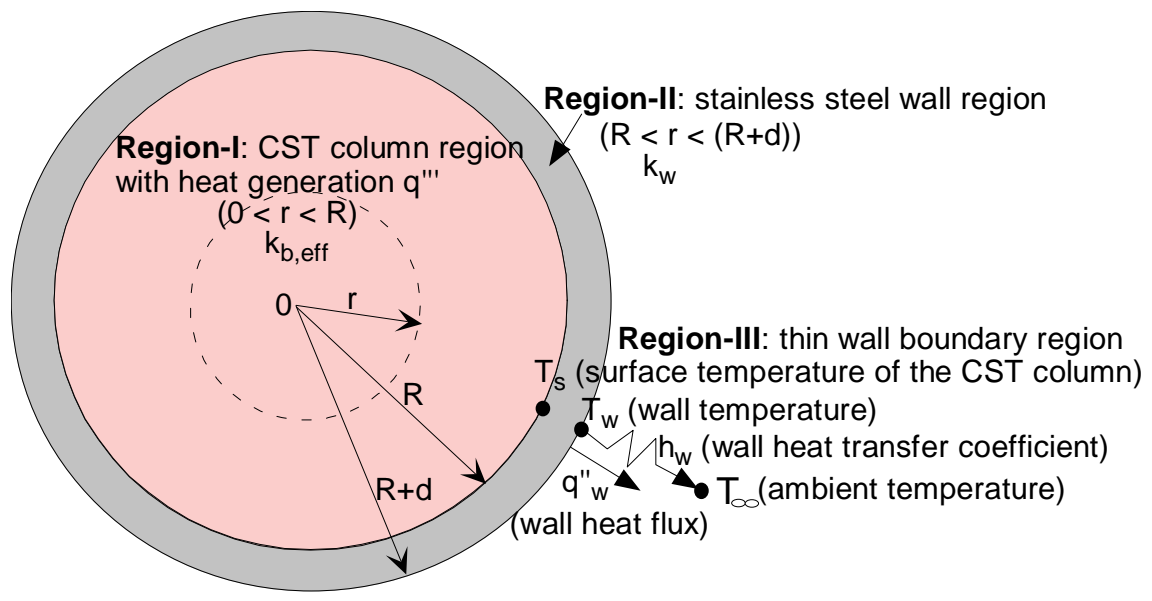

Figure 8. Graphical illustration of the heat transfer model of the Case-I CST column under natural convection cooling.

The wall surface temperature of the CST column $\left(T_{w}\right)$ can be obtained by eqs. (20) and (21) at $r=(R+d)$ in terms of the convection heat transfer coefficient $\left(h_{w}\right)$ at the column wall surface and the ambient temperature $\left(T_{\infty}\right)$ of Region-III shown in Fig. 9.

$$
\begin{aligned}
T_{w} & =T_{\infty}+\frac{q^{\prime \prime}{ }_{w}}{h_{w}} \\
& =T_{\infty}+\frac{q^{\prime \prime \prime}}{2 h_{w}}\left(\frac{R^{2}}{R+d}\right)
\end{aligned}
$$

From eqs. (17), (23), and (24), the center temperature of the CST-fluid bed region can be obtained in terms of the natural convection boundary condition and the ambient temperature.

$T(r=0)=T_{\infty}+\left(\frac{q^{\prime \prime \prime} R^{2}}{2}\right)\left\{\frac{1}{h_{w}(R+d)}+\frac{1}{k_{w}} \ln \left(\frac{R+d}{R}\right)\right\}+\frac{q^{\prime \prime \prime}}{4 k_{b, \text { eff }}} R^{2}$

The temperature distribution for each region can be non-dimensionalized in terms of the column wall temperature difference $\left(T_{w}-T_{\infty}\right)$ and the column radius $(\mathrm{R}+\mathrm{d})$ to examine the impacts of the design parameters on the CST temperature distributions. Nondimensional parameters shown in Fig. 10 are defined as follows:

$\eta=\frac{r}{(R+d)}$ and $\theta=\left(\frac{T-T_{\infty}}{T_{w}-T_{\infty}}\right)$

Temperature and length scales are non-dimensionalized in terms of the column temperature difference $\left(T_{w}-T_{\infty}\right)$ and the column radius $(\mathrm{R}+\mathrm{d})$ as shown in eq. (26).

For region-I $(0 \leq \eta \leq R /(R+d)$, the non-dimensional temperature distribution can be obtained from eqs. (17), (23), (24), and (26). 


$$
\theta(\eta)=1+\frac{B i}{2} \ln \left(\frac{R+d}{R}\right)+\frac{B i}{4}\left(\frac{k_{w}}{k_{b, \text { eff }}}\right)\left\{1-\left(\frac{R+d}{R}\right)^{2} \eta^{2}\right\}
$$

The Biot number (Bi) in eq. (27) is defined as the ratio of convection at the wall surface to the conduction through the column wall region. That is

$$
B i=\frac{h_{w} D}{k_{w}}=\frac{2(R+d) h_{w}}{k_{w}}
$$

Thus, the Biot number compares the relative magnitudes of surface convection and internal conduction resistance to heat transfer. A very low value for the Biot number means that internal conduction resistance is negligible in comparison with surface convection resistance. This in turn implies that the temperature will be nearly uniform throughout the conduction media.

The non-dimensional temperature distribution for the region-II $(R /(R+d) \leq \eta \leq 1)$ can be obtained from eqs. (22) and (26).

$$
\theta(\eta)=1-\frac{B i}{2} \ln \eta
$$

From eq. (27) the maximum temperature of the CST column with a thin wall thickness under steady-state condition becomes

$$
\theta_{\max } \approx 1+\frac{B i}{4}\left(\frac{k_{w}}{k_{b, \text { eff }}}\right)
$$

Thus, the non-dimensional temperature distributions inside the CST column and wall regions can be computed, and they can be compared with the steady-state numerical results to verify the model predictions. In this case, the numerical solution was obtained by solving the transient governing equations with a sequence of time steps until a steady-state solution is reached. Eq. (30) shows that the maximum temperature gradient is closely related to the wall Biot number and the ratio of thermal conductivity for the column wall region to the effective thermal conductivity of the composite CST column. For a given geometry and wall cooling conditions, the effective thermal conductivity is found to be the key parameter to control the maximum temperature difference between the column center and its wall.

Assuming that the material and thermal properties of the column system remain constant and the volumetric heat load is $100 \mathrm{Ci} /$ liter for the purpose of benchmarking, the steadystate temperature differences for the CST-salt solution columns between the column center and wall are about $27{ }^{\circ} \mathrm{C}$ for the 20 -in column, about $88^{\circ} \mathrm{C}$ for the 36 -in column, respectively. Figure 9 shows comparisons of theoretical values with the present computational results for the verification of the present calculations. It is shown that the present computational results are in good agreement with the theoretical results to within about $0.01 \%$.

For the enhanced cooling capability of the fully-loaded column design, the present SCIX column with the coolant pipe imbedded at its center was chosen. Steady-state temperature distributions within the present column containing a uniform heat load q"' were obtained by using a theoretical approach. Temperature boundary conditions are provided at the inner and outer wall boundaries of the 28 -in column with a volumetric 
heat source q"' under the same governing equation as the cylindrical geometry, eq. (13). The resulting equation for the temperature distribution $T(r)$ at a radial position $r$ from the column center becomes

$$
T(r)=T_{\text {wi }}-\frac{q^{\prime \prime \prime}\left(r^{2}-R_{i}{ }^{2}\right)}{4 k_{b, \text { eff }}}+\left[\frac{q^{\prime \prime \prime}}{4 k_{b, \text { eff }}}\left(R_{o}{ }^{2}-R_{i}{ }^{2}\right)-\left(T_{\text {wi }}-T_{\text {wo }}\right)\right]\left(\frac{\ln \left(r / R_{i}\right)}{\ln \left(R_{\mathrm{o}} / R_{i}\right)}\right)
$$

In eq. (31) the parameters $R_{i}$ and $R_{o}$ the inner and outer radii, and $T_{w i}$ and $T_{\text {wo }}$ are the inner and outer wall temperatures, respectively. In this case, the stainless steel wall regions at the inner and outer edges of the column are not considered for the simplified calculations.

The theoretical temperature distributions were compared with the modeling results for the 28-in column with a $300 \mathrm{Ci} /$ liter cesium loading, which corresponds to $1.485 \mathrm{~W} / \mathrm{liter}$. The validated results are shown in Fig. 10, where the model predictions and theoretical results show excellent agreement. Based on these evaluations, the benchmarking was considered complete and the model was considered validated.

\subsection{Modeling Results}

The validated model was subsequently used for thermal performance analysis of the SCIX column geometry loaded with CST or RF beads immersed in salt solution. Table 5 shows steady state maximum and minimum temperatures for the two ion exchange materials for Cases 1 and 2. The results reveal that the maximum temperature of the CST-salt solution column loaded to $257 \mathrm{Ci} /$ liter exceeds the liquid phase boiling point of $\sim 130^{\circ} \mathrm{C}$ under steady state conditions for Case 1 (maximum temperature: $156.0^{\circ} \mathrm{C}$ ). Figure 11 shows snapshots of the temperature distributions for the CST column under the Case 1 conditions at various times beginning with the initial temperature of $35^{\circ} \mathrm{C}$ and ending with the steady state temperature distribution. Transient temperature distributions across the packed CST bed between the inner and outer column walls are provided for various times in Fig. 12. Under Case 1 conditions with no coolant flow it is noted that the peak temperature location under steady state conditions is at the central coolant pipe wall. The results demonstrate that long-transient and steady-state results show a parabolic distribution along the center line of the column as predicted in eq. (27). Maximum and minimum temperatures versus time for the naturally-cooled CST column under Case 1 conditions are shown in Fig. 13. The results show that the maximum temperature of the CST column reaches $95^{\circ} \mathrm{C}$ in $\sim 3$ days and reaches boiling in 6.4 days. Approximately 40 days is required for the CST-salt solution column to reach the steady-state temperature of $156.0^{\circ} \mathrm{C}$, although this condition would never actually be observed due to the aforementioned solution boiling. The relatively slow transient thermal response of the column to the heat load is mainly due to the large heat capacity of the salt solution. The results demonstrate that a naturally-cooled (ambient cell temperature of $35^{\circ} \mathrm{C}$ with no forced ventilation), 28-in CST column under Case 1 conditions can sit stagnant without boiling for 6 days.

Figure 14 shows snapshots of the RF column temperature profiles at various times under Case 1 modeling conditions. Maximum and minimum temperatures within the RF column are provided for various times in Fig. 15. Replacement of CST media with RF 
resin, which involves a heat loading reduction from 257 to $134 \mathrm{Ci} /$ liter (as well as associated changes in effective thermal conductivity described earlier), reduces the maximum column temperature significantly. Even under steady state conditions for this bounding model case, the maximum temperature for the cesium loaded RF column is only $87.5{ }^{\circ} \mathrm{C}$. The maximium temperature observed after 3 days under Case 1 conditions is $31^{\circ} \mathrm{C}$ lower with RF versus CST. Transient temperature distributions across the packed RF bed between the inner and outer column walls are provided for various times in Fig. 16.

Figure 17 directly compares the transient results of maximum and minimum column temperatures for the CST and RF columns under the Case 1 modeling conditions. Table 6 provides the maximum and minimum temperatures within the CST and RF columns at various times. The results show that the maximum temperature of the CST column increases $24^{\circ} \mathrm{C}$ in the first day, which is two times higher than the increase observed with the RF column in the same period.

Table 7 shows sensitivity analysis results for the steady-state CST and RF column temperatures associated with increasing the external ambient air temperature from 35 to $55^{\circ} \mathrm{C}$. Transient sensitivity analysis results for the CST column are graphically compared in Fig. 18. As expected, a higher ambient air temperature results in faster temperature increases and a higher maximum temperature. For $55^{\circ} \mathrm{C}$ ambient air, the SCIX column is initially heated rather than cooled by the ambient air since the Case 1 scenario involves an initial column temperature of $35^{\circ} \mathrm{C}$. As a result of this heating effect, the column temperature increases linearly during the first 48 hours and then is governed by the internal heating source associated with cesium radiolytic decay. Figure 19 shows sensitivity analysis results for the thermal responses of the RF column at ambient air temperatures of 35 and $55^{\circ} \mathrm{C}$. The modeling results show that when the ambient temperature changes from 35 to $55^{\circ} \mathrm{C}$ the maximum bed temperature increases by $16-17^{\circ} \mathrm{C}$ for CST and RF columns in 10 days. For RF, the maximum steady-state column temperature with $55^{\circ} \mathrm{C}$ ambient air of $105.1^{\circ} \mathrm{C}$ still does not exceed the liquid phase boiling point. An ambient air temperature of $55^{\circ} \mathrm{C}$ decreases the time required for the CST column to reach boiling from 6.4 days to just under 5 days. The results show that increasing the ambient temperature from 35 to $55^{\circ} \mathrm{C}$ does not greatly impact the maximum temperature or the heat rate.

The transient thermal response of a conduction medium containing a heat source to the cooling environment at a lower temperature is closely related to its thermal diffusivity. The thermal diffusivity, $\alpha$, is defined as the ratio of thermal conductivity to the product of density and specific heat. As shown in Table 8, the column media during no flow situations have small $\alpha$ values of $1.03 \times 10^{-3} \mathrm{~cm}^{2} / \mathrm{sec}$ for CST packed beds and $1.46 \mathrm{x}$ $10^{-3} \mathrm{~cm}^{2} / \mathrm{sec}$ for RF beds. This parameter is a measure of temperature-wave penetration depth for a given time. Detailed results for thermal transient durations required to reach steady state conditions under the Case 1 modeling conditions are quantitatively compared for the two ion exchange media in Table 8. The modeling results are in good agreement with theoretical predictions in terms of the transient response period. The time required to reach steady state thermal conditions is about 40 days for the CST column and about 28 days for the RF column. As shown in Figs. 18 and 19, the CST/RF-salt solution columns with no process flow have slow thermal responses to heat loads due to the low effective thermal diffusivities for the packed beds. Table 9 provides the maximum temperature results at various times for the Case I 
model for both column types cooled by natural convection at ambient temperatures of 35 and $55^{\circ} \mathrm{C}$.

The present work assumed that each spherical Resorcinol-Formaldehyde (RF) resin particle had about $66 \%$ pore volume, which was occupied by salt solution within the SCIX column. This corresponds to a total porosity for the packed RF bed of $80 \%$. The impact of such a high porosity on the thermal response under Case 1 conditions was evaluated as part of the model sensitivity analysis. Table 10 shows sensitivity results of the steady state temperatures for different RF resin bead porosities under the Case 1 model. The results show that the maximum bed temperature increases about $12^{\circ} \mathrm{C}$ for the steady-state naturally-cooled column when RF resin porosity changes from the nominal value of $66 \%$ to $0 \%$. The maximum steady-state column temperature with $0 \%$ porosity of $100.1^{\circ} \mathrm{C}$ still does not exceed the liquid phase boiling point. Transient temperature results for the naturally-cooled RF column with three different resin porosities are presented during the first 10 days' period following initiation of the Case 1 scenario in Fig. 20. Table 11 shows a summary of the maximum temperatures at various times for the three different resin porosities during the first 2 days. The results show that when the RF resin porosity changes from the nominal value of $66 \%$ to $0 \%$ (nonporous), the maximum column temperature increases by only $\sim 5^{\circ} \mathrm{C}$ in the first two days. This analysis confirms that the high nominal value selected for the RF bead porosity does not greatly impact the thermal analysis results.

The thermal response for the SCIX column design with an active engineered cooling system was evaluated as Case 2. As shown in Figure 2, the cooling system consists of one central cooling pipe and four half-pipe water jackets vertically attached to the external wall surface at $90^{\circ}$ circumferential separation. The cooling system was assumed to maintain a constant bulk fluid temperature of $25^{\circ} \mathrm{C}$ during operations. Case 2 was considered to be less bounding and more representative of a realistic operations scenario. Case 1 assumed simultaneous occurrence of the following events: maximum cesium loading, loss of salt solution flow, and loss of coolant flow, whereas Case 2 involved the same bounding conditions as Case 1 but with the engineered cooling system available. The modeling calculations assumed that the cooling system maintained delivery of $25^{\circ} \mathrm{C}$ water at $6.25 \mathrm{gpm}$ for each of the four side jackets and 12.5 gpm for the central cooling pipe. Figure 21 shows steady state temperature distributions for the CST column under Case 2 conditions. The results show that maximum temperature of the CST column under these conditions is $62.7^{\circ} \mathrm{C}$. Steady state temperature distributions for the fixed RF column are shown in Fig. 22, where the maximum temperature is predicted to be $40.7^{\circ} \mathrm{C}$. For the CST column the peak column temperature is about $93^{\circ} \mathrm{C}$ lower for Case 2 than was observed for Case 1 . Clearly, the engineered coolant system greatly impacts and improves heat transfer from the column under no process flow conditions. Furthermore, the coolant system maintains the maximum temperatures of columns containing either ion exchange media near or below the expected temperature limits required to maintain optimal cesium removal performance $\left(50-80^{\circ} \mathrm{C}\right.$ for $\mathrm{CST}$ and $65^{\circ} \mathrm{C}$ for $\left.\mathrm{RF}\right)$.

Case 3 was considered as a nominal operational case since it involved process flow of salt solution through the SCIX column. However, the results of the Case 3 calculations are considered conservative since no heat transfer to the system boundary was assumed. Table 12 provides steady state predictions of the temperature differences from the top to the bottom of the column for three potential bed heights under nominal operating conditions during downflow. These values are also representative of the 
temperature increase of the mobile liquid phase during column processing. The results indicate that when the salt process flowrate is $5 \mathrm{gpm}$ through a $25 \mathrm{ft}$ tall column, the bulk temperature increase over the entire column (top to bottom) will be about $2.8^{\circ} \mathrm{C}$ for the column loaded with CST material and about $1.4^{\circ} \mathrm{C}$ for the column loaded with RF resin material. This means, for example, that salt solution which enters a $25 \mathrm{ft} \mathrm{CST} \mathrm{column} \mathrm{at}$ $35^{\circ} \mathrm{C}$ and a flowrate of $5 \mathrm{gpm}$ will exit the column at $37.8^{\circ} \mathrm{C}$. Smaller temperature increases were predicted for shorter columns at $5 \mathrm{gpm}$ since the liquid residence time in the column was shorter. Smaller temperature increases would be predicted for faster flow rates at each column length as well for the same reason (shorter residence time).

For stagnant column flow cases a forced convective cooling mechanism involving the the engineered central cooling pipe has a significant impact on the peak column temperature and results in a location change of the peak temperature from the interior coolant pipe wall to near the midpoint of the ion exchange bed. Figure 23 compares local nondimensionalized temperature profiles for a $100 \%$ naturally-cooled column with no active cooling system (Case 1 ) and a partially naturally-cooled column with an active engineered cooling system (Case 2) across the packed ion exchange bed from the interior to the exterior walls. This observation raised the possibility of a column design simplification involving removal of the external cooling jackets. Additional analysis was conducted for CST columns where column heating from radiolysis was more significant in order to determine the temperature profiles resulting from using only the central cooling pipe. Figure 24 compares predicted temperature distributions along the radial line A-A' of a CST column for various cooling system designs. The results demonstrate that the central cooling pipe provides the primary cooling mechanism in reducing the peak column temperature. Table 14 shows a quantitative comparison of maximum column temperatures under the various cooling system designs. Operating the cooling system with only the central pipe results in an increase in the maximum temperature to only $80^{\circ} \mathrm{C}$, whereas external jacket cooling alone results in a maximum temperature increase to $114^{\circ} \mathrm{C}$. As discussed earlier, utilization of both the central cooling pipe and the external jacket gives a steady state temperature of $63^{\circ} \mathrm{C}$. The central cooling pipe is clearly the most effective part of the cooling system, however, given the uncertainty in the operating temperature limits for CST, it is unclear whether removal of the cooling jackets is advisable. 

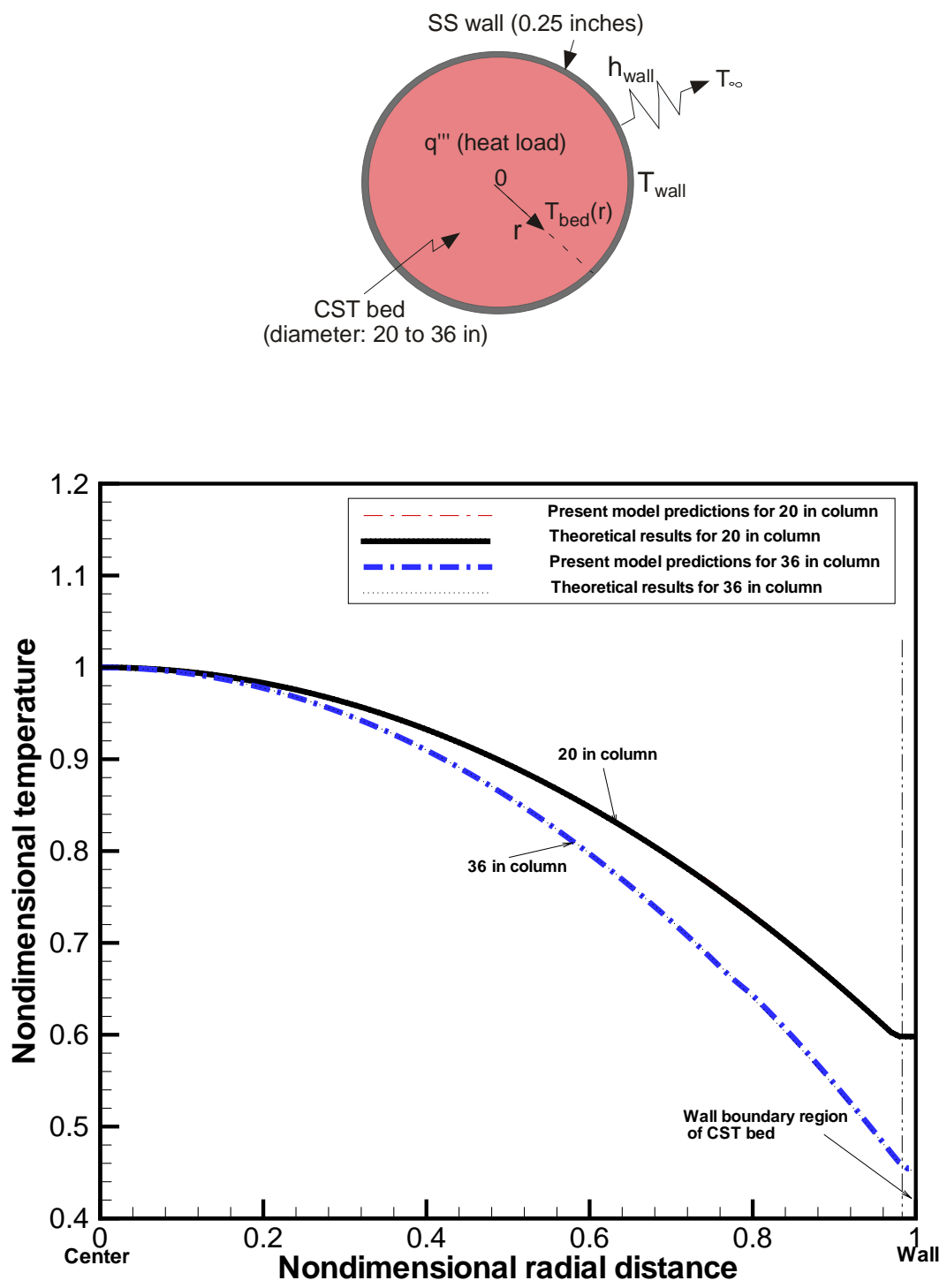

$$
\begin{gathered}
\text { (nondimensional radial distance } \eta=\frac{r}{R+d}, \\
\text { nondimensional temperature } \left.\theta_{00}=\frac{T(t \rightarrow \infty, r)-T_{\infty}}{T(t \rightarrow \infty, r=0)-T_{\infty}}\right)
\end{gathered}
$$

Figure 9. Comparison of steady state results between the numerical computations and theoretical results for the cylindrical column with $100 \mathrm{Ci} /$ liter heat load for model benchmarking. 

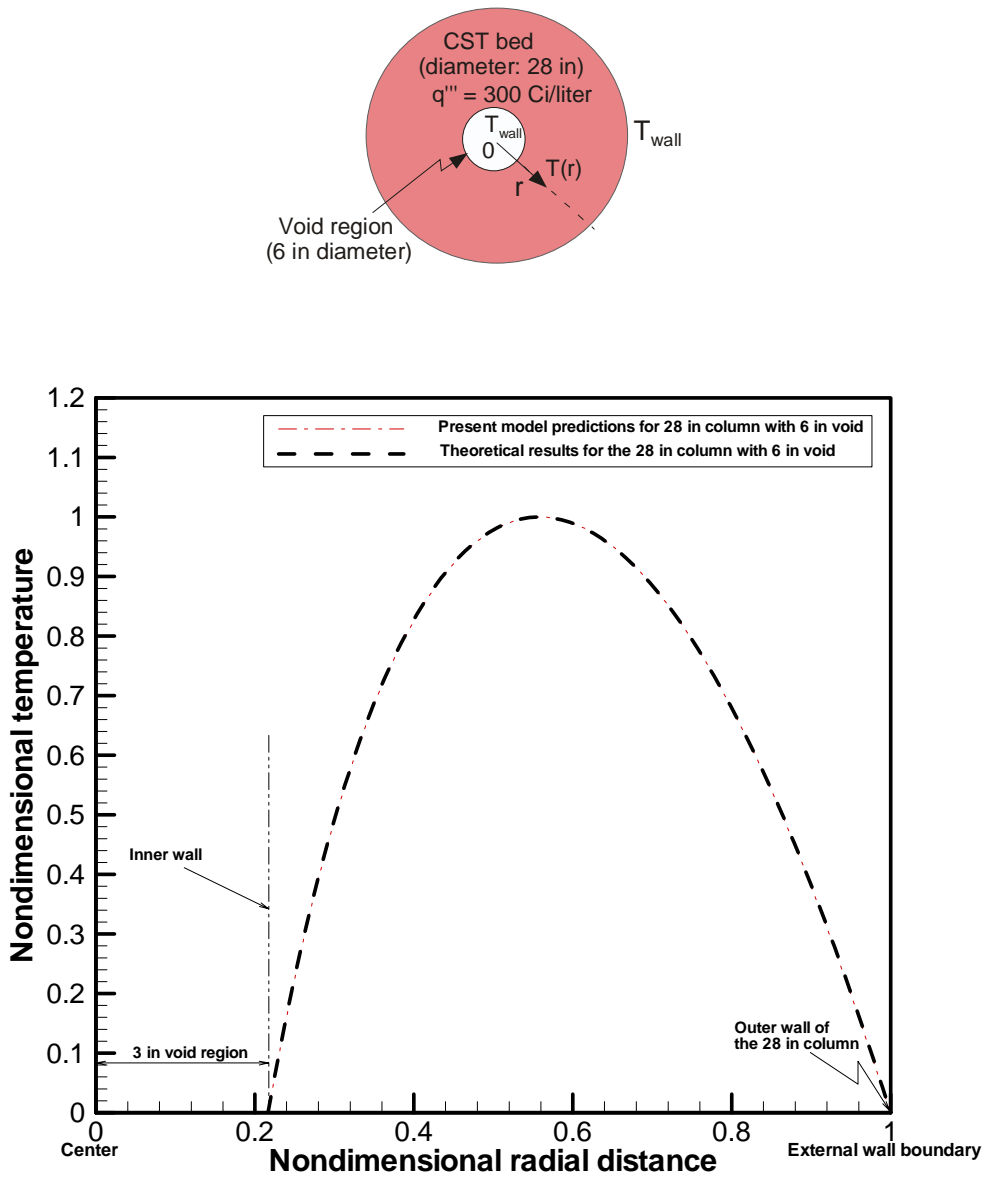

$$
\begin{gathered}
\text { (nondimensional radial distance } \eta=\frac{r}{R+d}, \\
\text { nondimensional temperature } \left.\theta_{0 w}=\frac{T(t \rightarrow \infty, r)-T_{\text {wall }}}{T\left(t \rightarrow \infty, r=r_{\text {max }}\right)-T_{\text {wall }}}\right)
\end{gathered}
$$

Figure 10. Comparison of steady state results between the numerical computations and theoretical results for the annular-type column with $300 \mathrm{Ci} /$ liter heat load for model benchmarking.

Table 5. Summary of steady-state results for the nominal bounding models.

\begin{tabular}{|c|c|c|c|}
\hline $\begin{array}{c}\text { Column } \\
\text { systems }\end{array}$ & Models & $\begin{array}{c}\text { Min. bed temperature } \\
\left({ }^{\circ} \mathbf{C}\right)\end{array}$ & $\begin{array}{c}\text { Max. bed temperature } \\
\left({ }^{\circ} \mathbf{C}\right)\end{array}$ \\
\hline \multirow{2}{*}{ CST column } & Case 1 & 83.8 & 156.0 \\
\cline { 2 - 4 } & Case 2 & 25.5 & 62.7 \\
\hline \multirow{2}{*}{ RF column } & Case 1 & 61.8 & 87.5 \\
\cline { 2 - 4 } & Case 2 & 25.3 & 40.7 \\
\hline
\end{tabular}



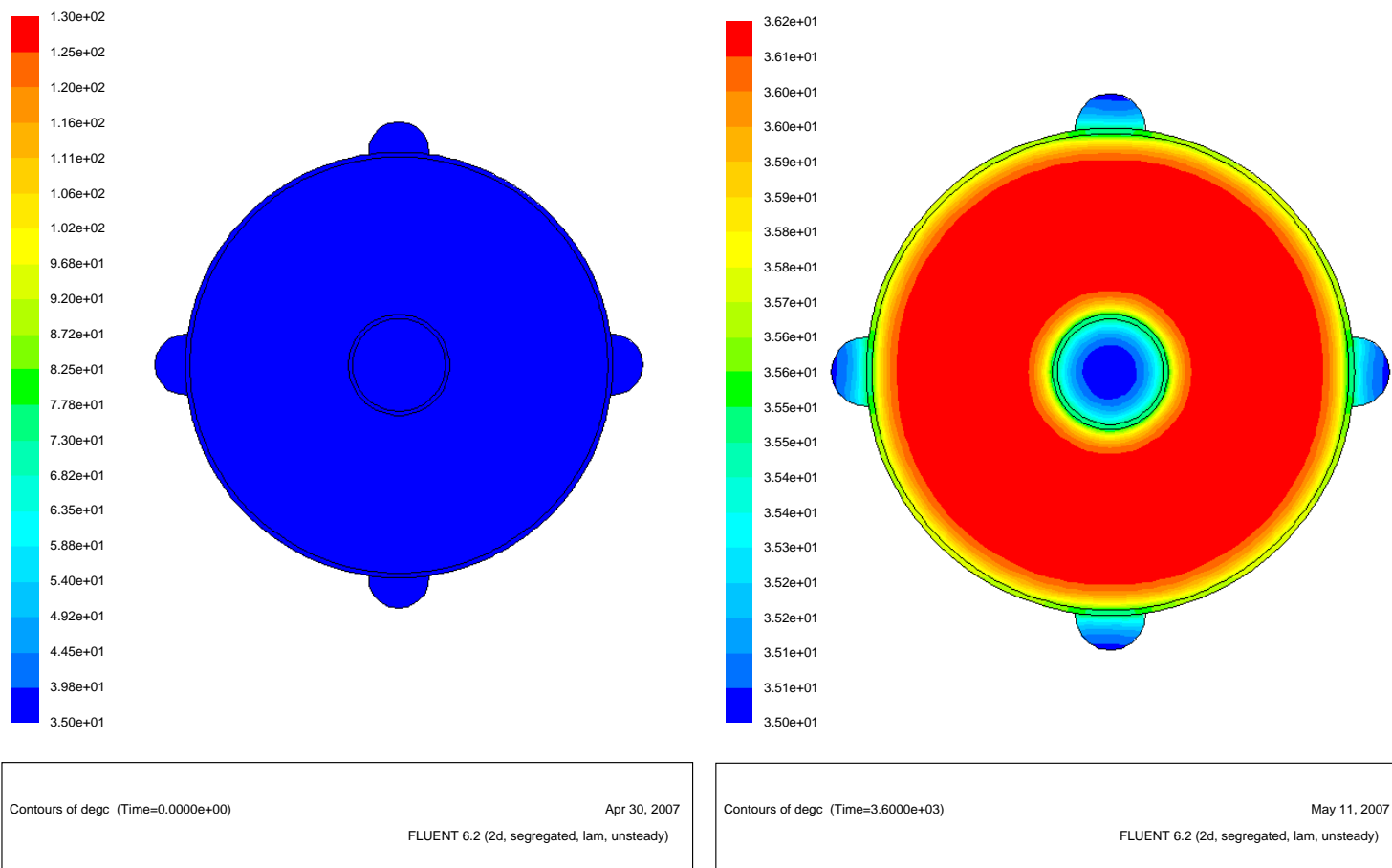

$\left(\mathrm{t}=0 \mathrm{sec}, \mathrm{T}_{\mathrm{i}}=35 \mathrm{C}\right)$
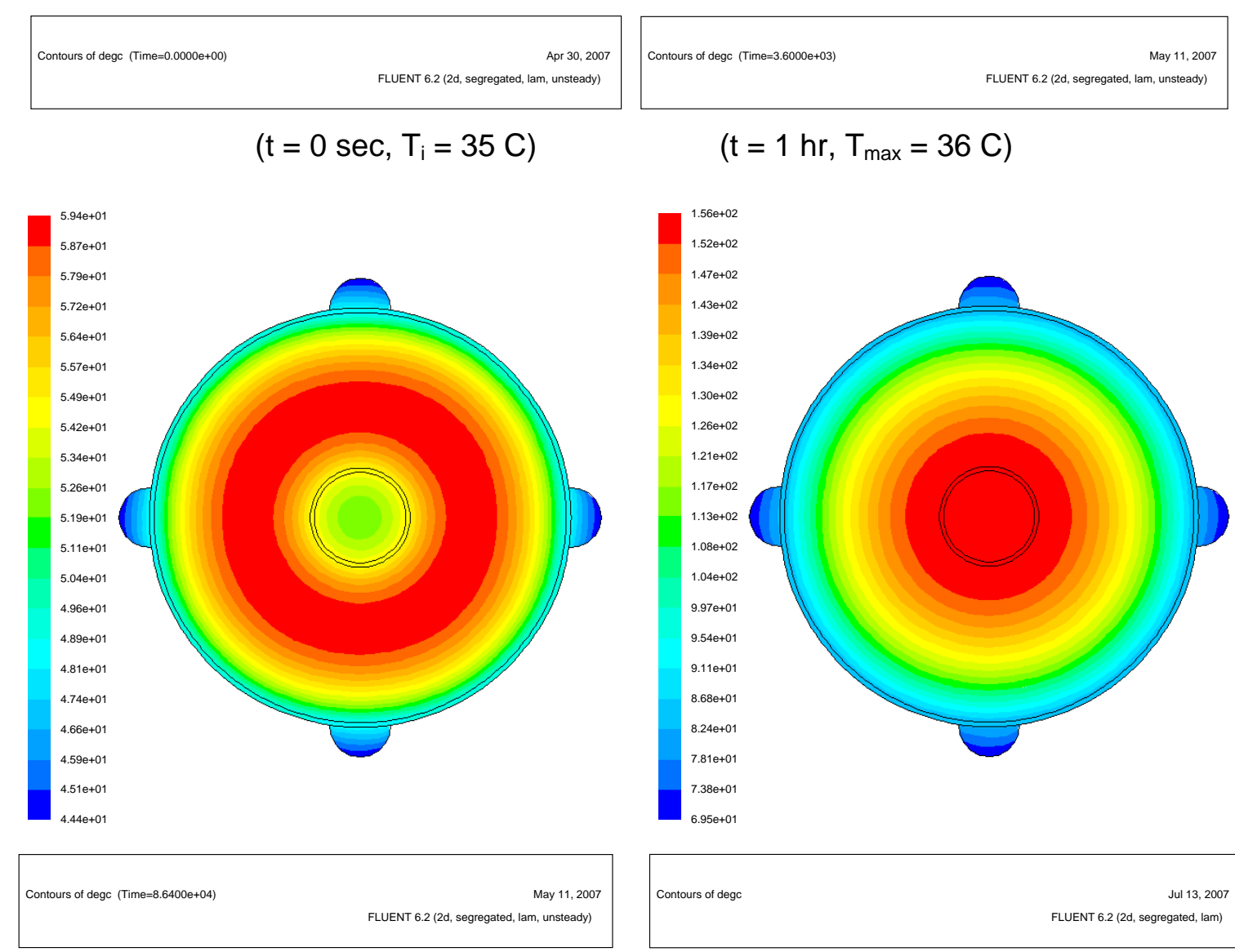

$\left(\mathrm{t}=1 \mathrm{hr}, \mathrm{T}_{\max }=36 \mathrm{C}\right)$

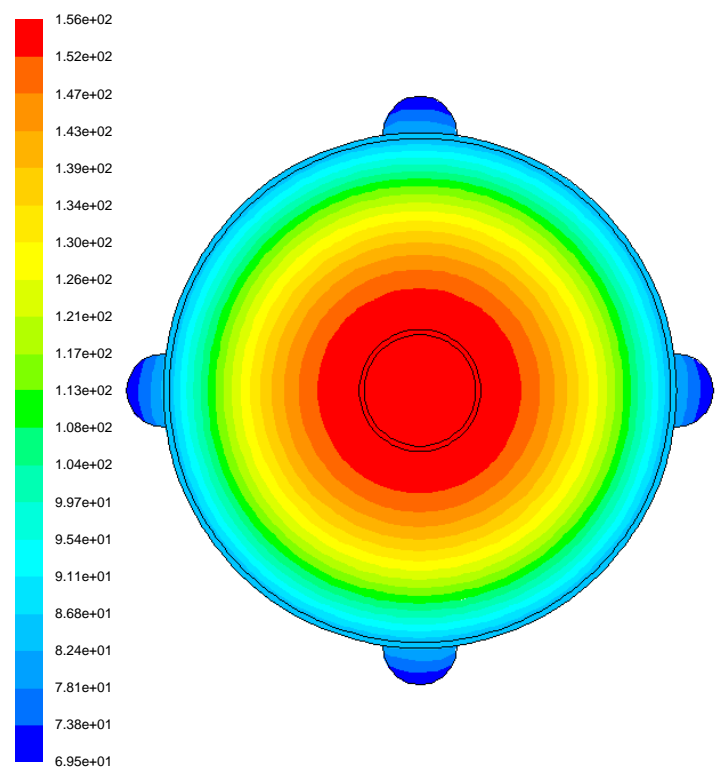

$\left(\mathrm{t}=24 \mathrm{hrs}, \mathrm{T}_{\max }=60 \mathrm{C}\right)$

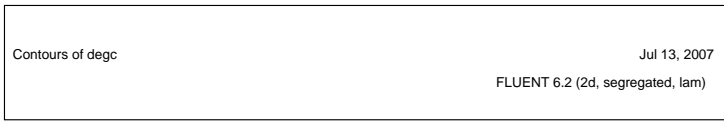

(Steady state, $\mathrm{T}_{\max }=156 \mathrm{C}$ )

Figure 11. Transient snapshots for CST column temperature distributions under the Case 1 model 

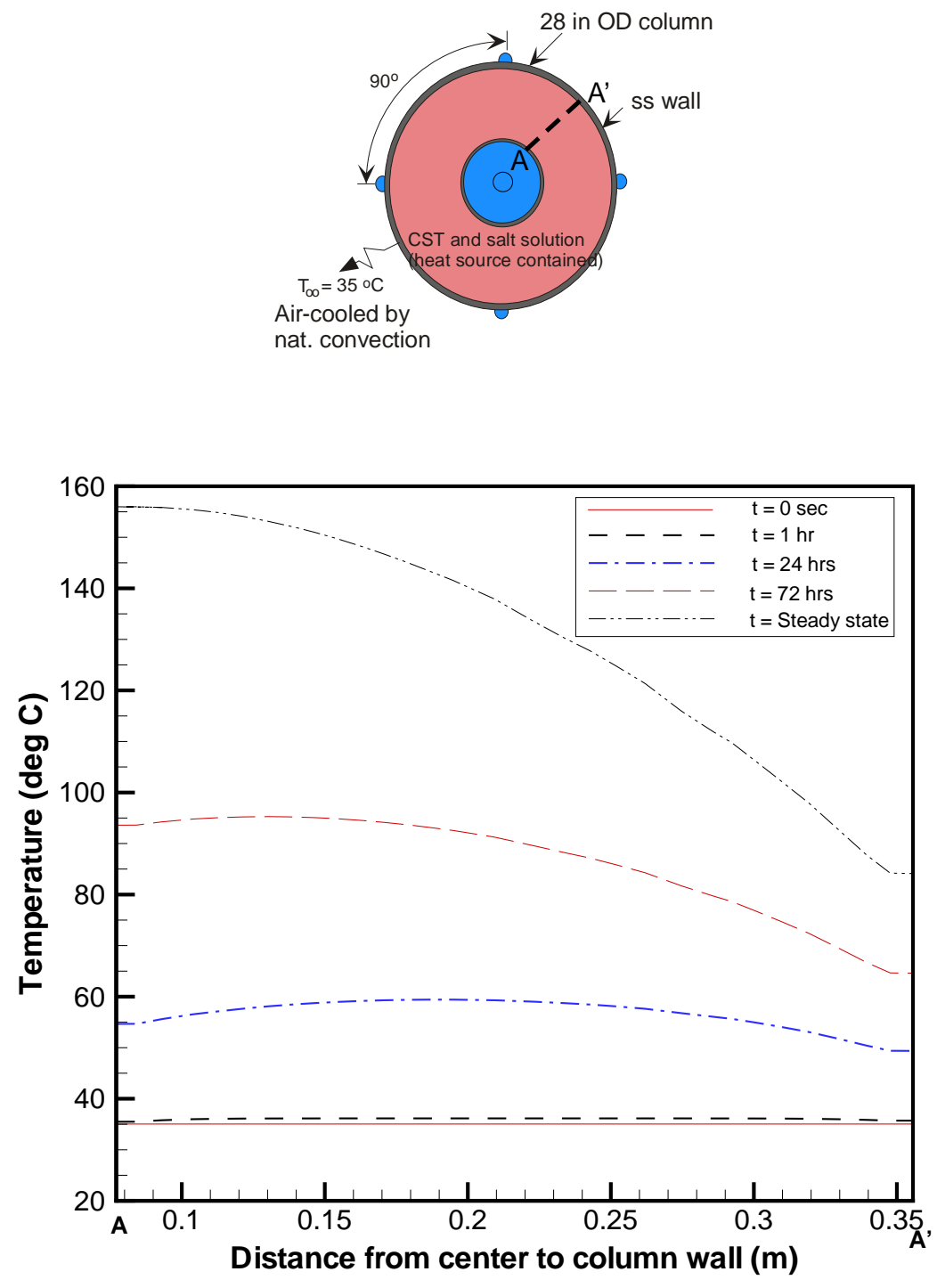

Figure 12. Transient and steady-state temperature distributions for the bounding CST model along the line A-A' under the Case 1 model 


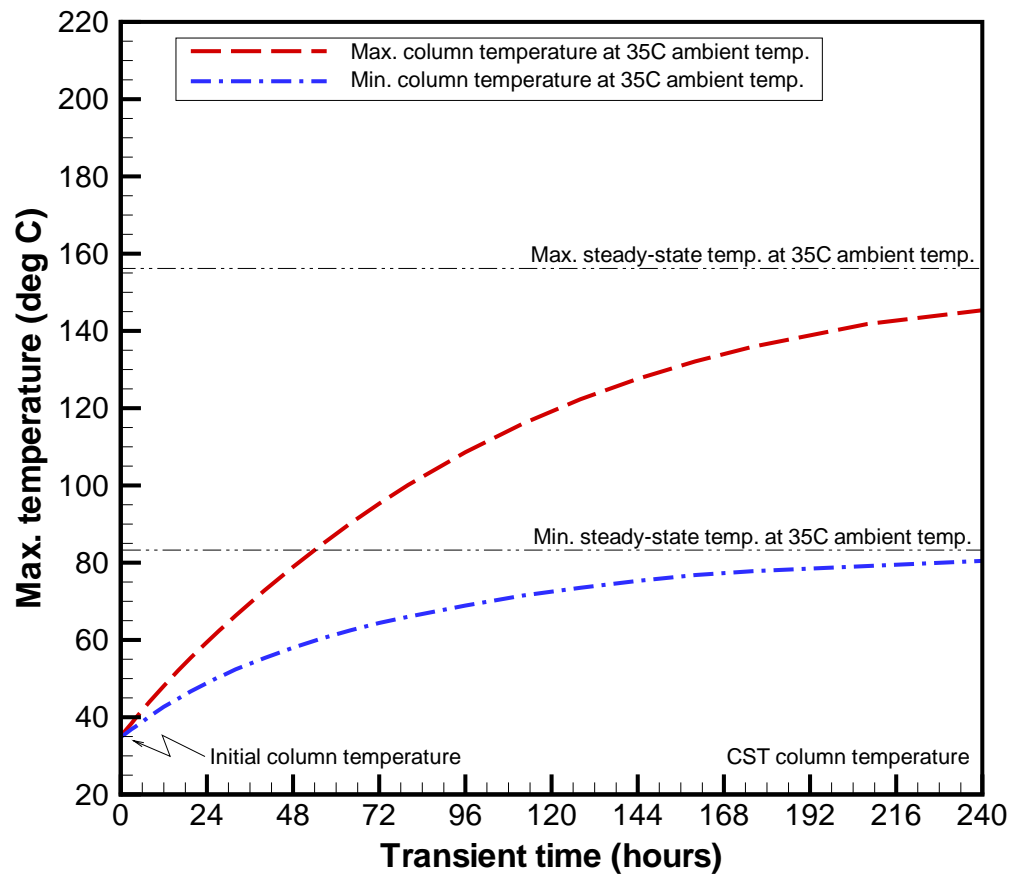

Figure 13. Transient thermal responses of CST column containing $257 \mathrm{Ci} /$ liter radioactive heat source under the Case 1 model 

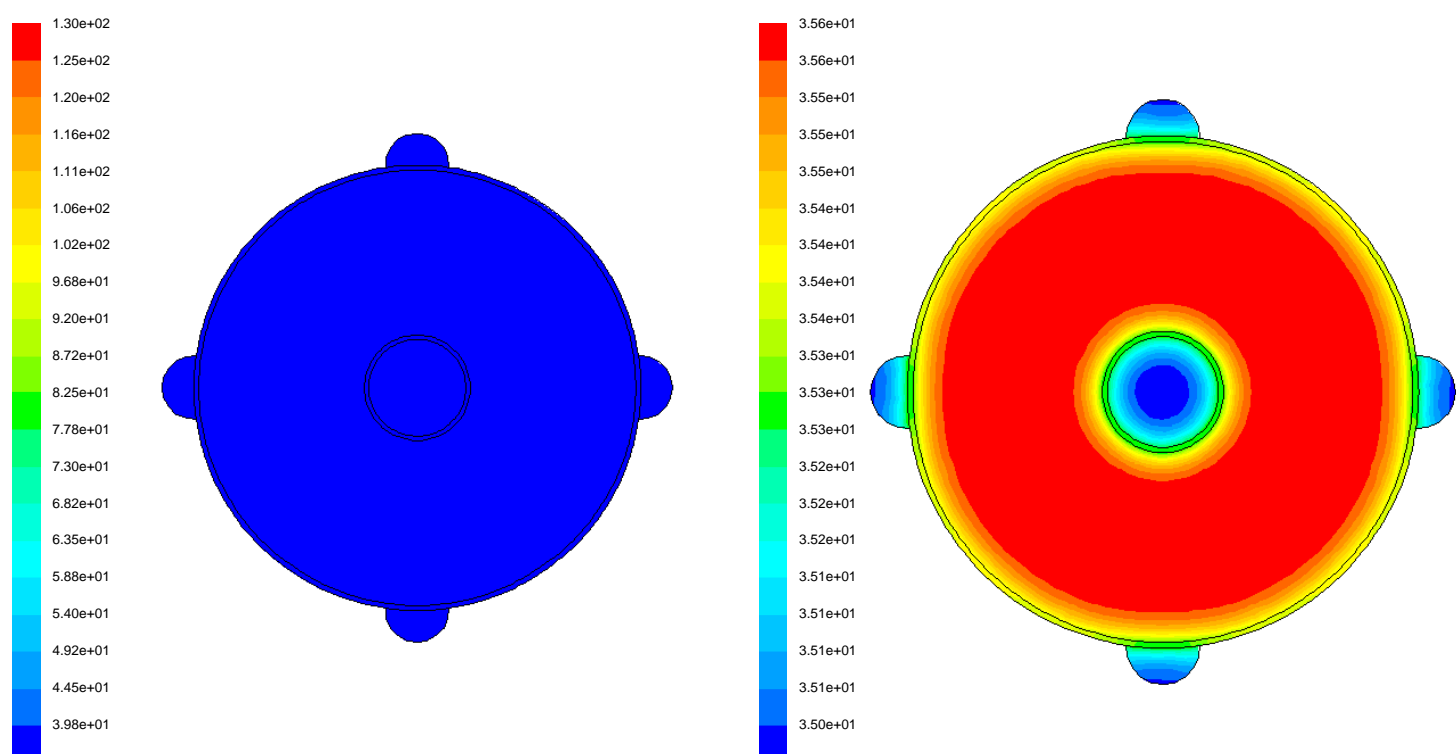

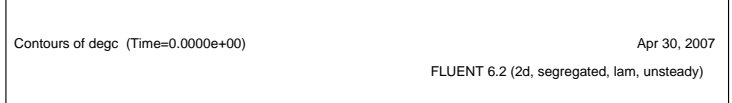

$\left(t=0 \mathrm{sec}, \mathrm{T}_{\mathrm{i}}=35 \mathrm{C}\right)$
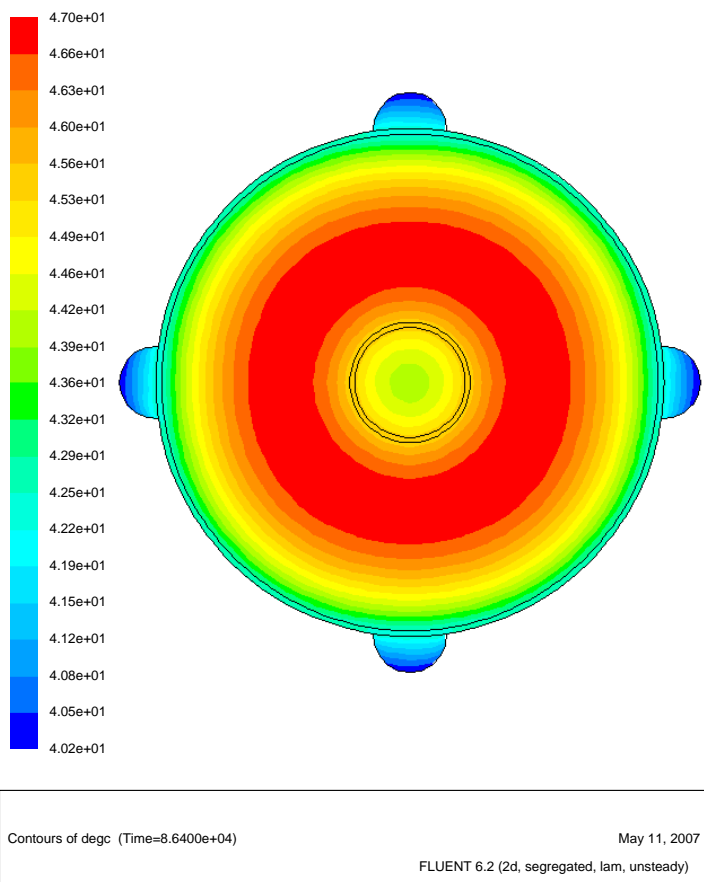

$\left(\mathrm{t}=24 \mathrm{hrs}, \mathrm{T}_{\max }=47 \mathrm{C}\right)$

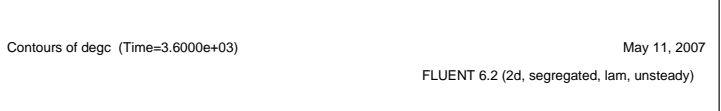

$\left(\mathrm{t}=1 \mathrm{hr}, \mathrm{T}_{\max }=36 \mathrm{C}\right)$

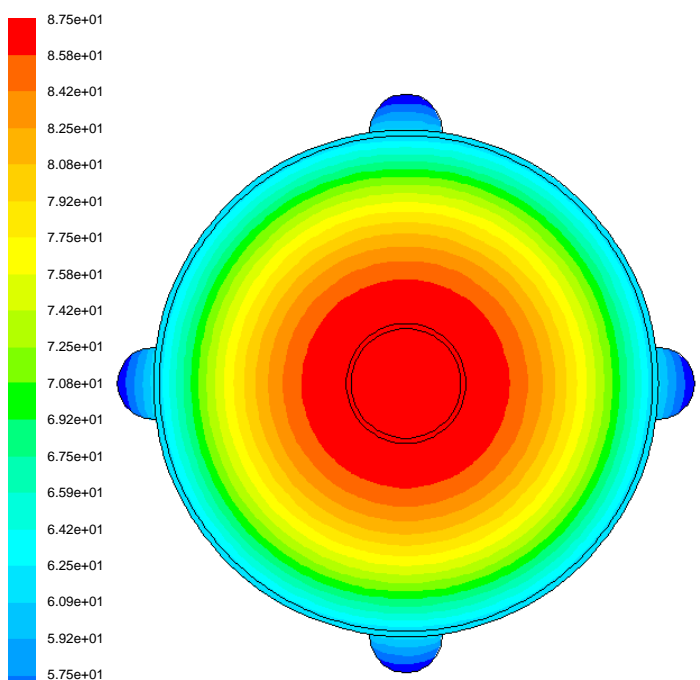

$5.42 \mathrm{e}+01$

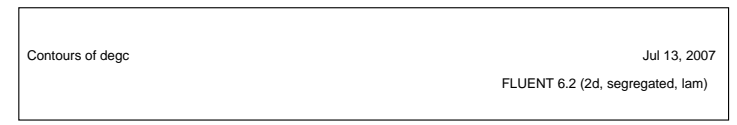

(Steady state, $\mathrm{T}_{\max }=87.5 \mathrm{C}$ )

Figure 14. Transient snapshots for RF column temperature distributions under the Case 1 model 


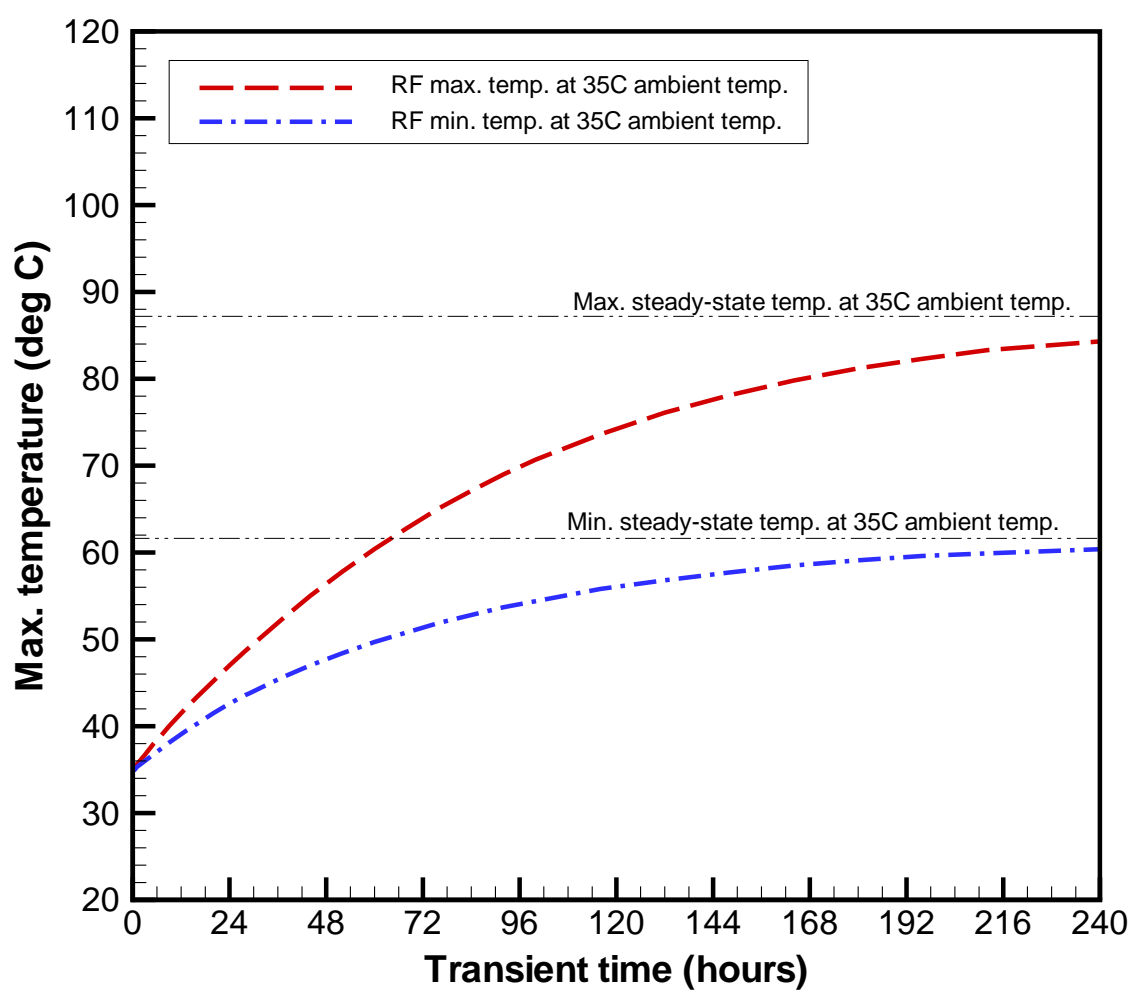

Figure 15. Transient thermal response of the fixed RF column containing $133.5 \mathrm{Ci} /$ liter radioactive heat source under the Case 1 model 

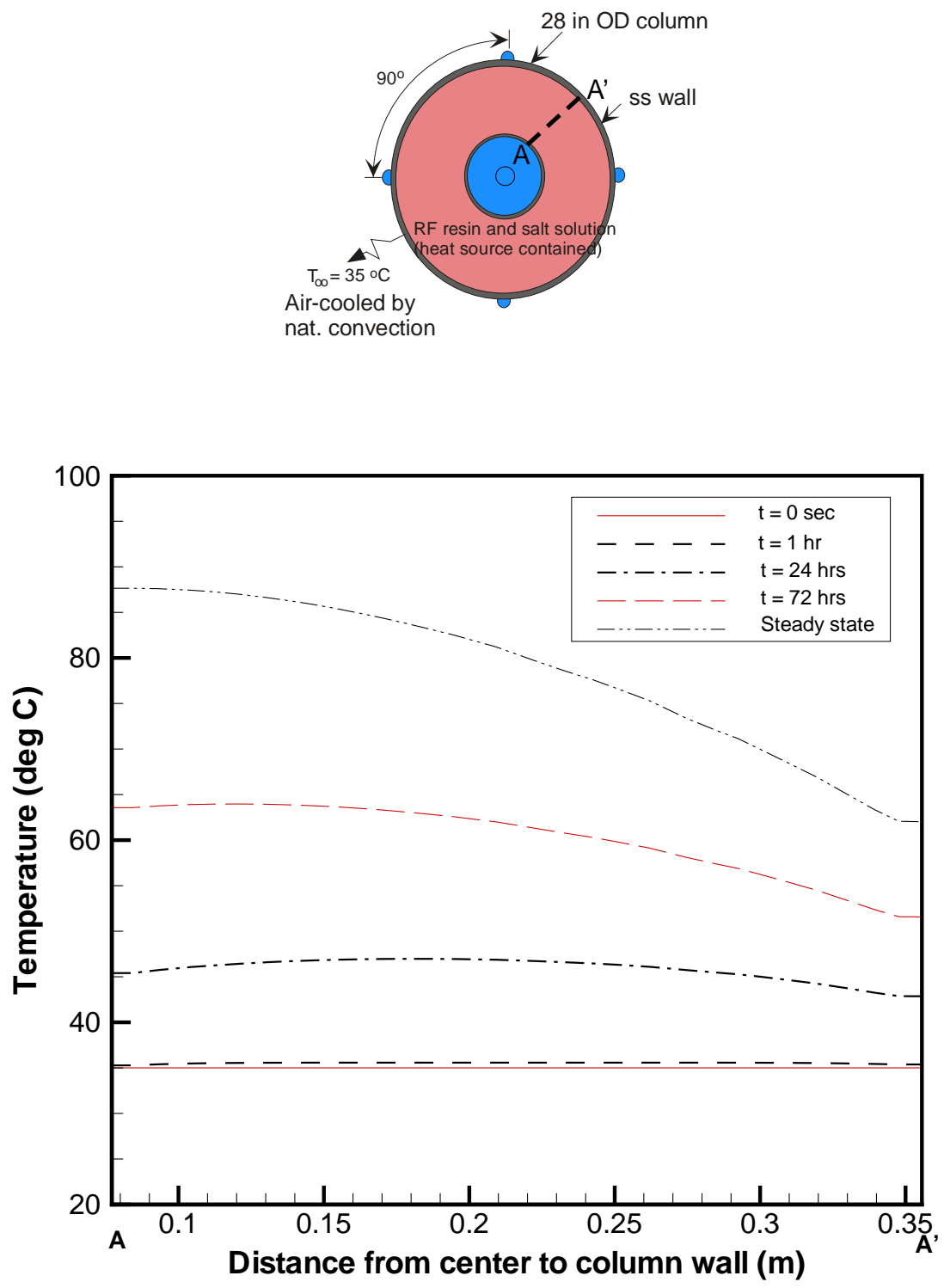

Figure 16. Transient and steady-state temperature distributions for fixed RF column along the line A-A' under the Case 1 model 


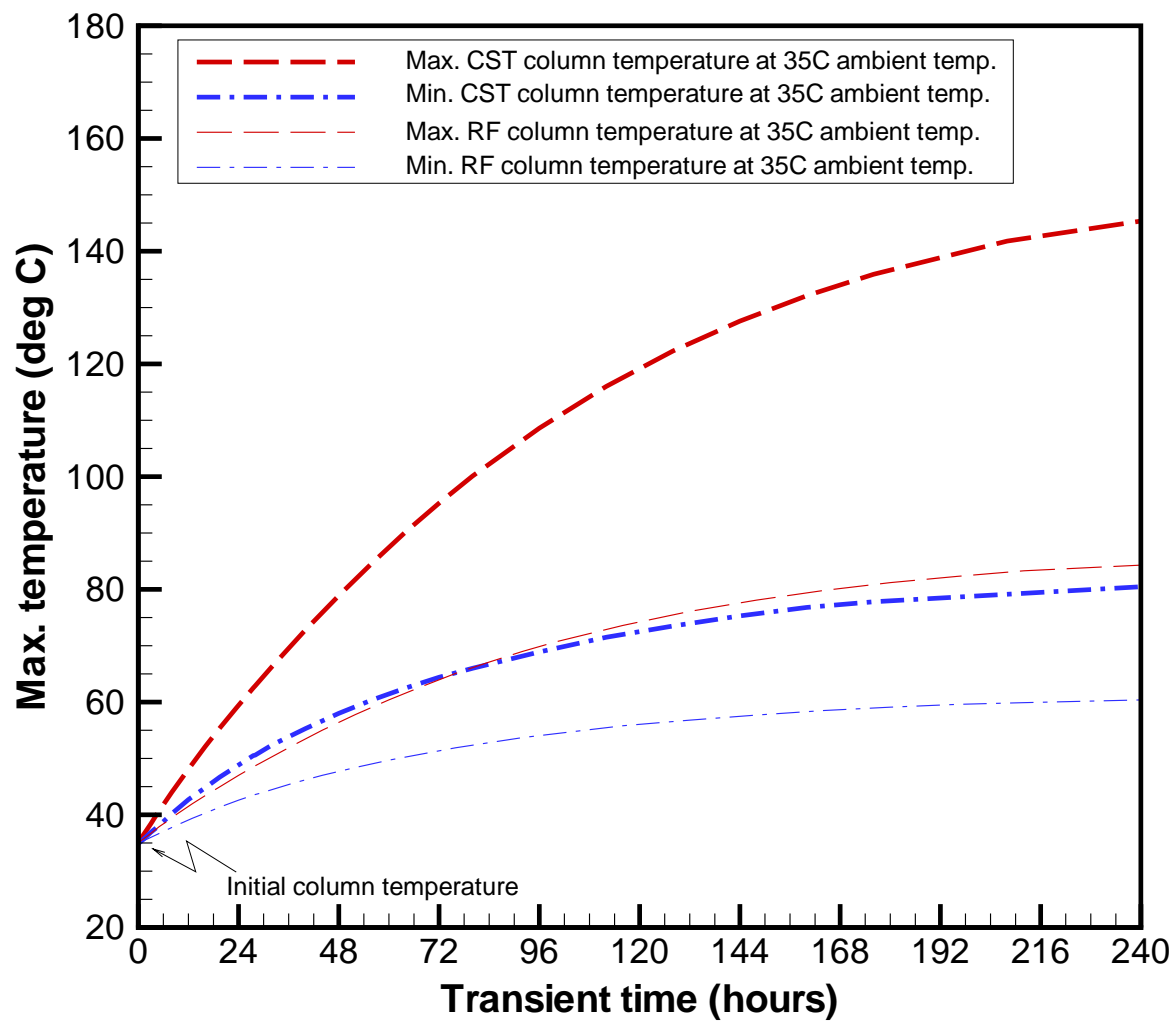

Figure 17. Comparison of transient thermal responses to the CST and RF loadings for $35^{\circ} \mathrm{C}$ initial column temperature (Case 1 ). 
Page: $\quad 34$ of 45

Table 6. Transient and steady state results of maximum column temperatures for the Case-I model of 28-in CST/RF columns cooled by natural convection boundary with $35^{\circ} \mathrm{C}$ ambient temperature.

\begin{tabular}{|c|c|c|c|c|}
\hline \multirow{2}{*}{\begin{tabular}{c}
\multirow{2}{*}{$\begin{array}{c}\text { Transient time } \\
\text { (hours) }\end{array}$} \\
\cline { 2 - 5 }
\end{tabular}} & \multicolumn{4}{|c|}{ Ambient air temperature (35 ${ }^{\circ} \mathrm{C}$ ) } \\
\cline { 2 - 5 } & Max. & Min. & Max. & Min. \\
\hline Initial condition & 35.0 & 35.0 & 35.0 & 35.0 \\
\hline 0.5 & 35.6 & 35.2 & 35.3 & 35.0 \\
\hline 1 & 36.2 & 35.5 & 35.6 & 35.3 \\
\hline 4 & 39.6 & 37.5 & 37.3 & 36.4 \\
\hline 8 & 44.0 & 40.2 & 39.5 & 37.8 \\
\hline 10 & 46.1 & 41.5 & 40.5 & 38.4 \\
\hline 16 & 52.1 & 44.8 & 43.4 & 40.3 \\
\hline 24 (1 day) & 59.4 & 48.8 & 47.0 & 42.6 \\
\hline 32 & 66.3 & 52.4 & 50.3 & 44.5 \\
\hline 48 (2 days) & 78.9 & 58.0 & 56.4 & 47.7 \\
\hline 144 (6 days) & 127.6 & 75.3 & 77.6 & 57.5 \\
\hline Steady state & 156.0 & 83.8 & 87.5 & 61.8 \\
\hline
\end{tabular}


Table 7. Comparison of the steady state temperatures for two different ambient temperatures under the Case 1 model.

\begin{tabular}{|c|c|c|c|}
\hline \multirow{2}{*}{\multicolumn{2}{|c|}{ Case 1 model$^{\star}$}} & \multicolumn{2}{|c|}{ Ambient temperature } \\
\hline & & $35^{\circ} \mathrm{C}$ & $55^{\circ} C^{\star \star}$ \\
\hline \multicolumn{2}{|c|}{$\begin{array}{l}\text { Effective thermal conductivity for the CST-loaded } \\
\text { column (W/mK) }\end{array}$} & \multicolumn{2}{|c|}{0.4125} \\
\hline \multicolumn{2}{|c|}{$\begin{array}{l}\text { Effective thermal conductivity for the RF-loaded } \\
\text { column (W/mK) }\end{array}$} & \multicolumn{2}{|c|}{0.5987} \\
\hline \multicolumn{2}{|c|}{ Thermal diffusivity $\left(\mathrm{cm}^{2} / \mathrm{sec}\right)$} & \multicolumn{2}{|c|}{$1.0320 \times 10^{-3}$} \\
\hline \multicolumn{2}{|c|}{ CST Heat load (Ci/liter) [W/liter] } & \multicolumn{2}{|c|}{$257.2[1.273]$} \\
\hline \multicolumn{2}{|c|}{ RF Heat load (Ci/liter) [W/liter] } & \multicolumn{2}{|c|}{$133.5[0.661]$} \\
\hline \multicolumn{2}{|c|}{ Wall heat transfer coeff. $\left(h_{w}\right)$} & \multicolumn{2}{|c|}{$1.5 \mathrm{~W} / \mathrm{m}^{2} \mathrm{~K}$ (natural convection) } \\
\hline \multirow[t]{2}{*}{ CST column } & Max. Temperature & $156.0^{\circ} \mathrm{C}$ & $171.6^{\circ} \mathrm{C}$ \\
\hline & Column wall temperature & $83.8^{\circ} \mathrm{C}$ & $99.5^{\circ} \mathrm{C}$ \\
\hline \multirow[t]{2}{*}{ RF column } & Max. Temperature & $87.5^{\circ} \mathrm{C}$ & $105.1{ }^{\circ} \mathrm{C}$ \\
\hline & Column wall temperature & $61.8^{\circ} \mathrm{C}$ & $79.4^{\circ} \mathrm{C}$ \\
\hline
\end{tabular}

Note: * Model considered for the bounding case

**Used for sensitivity analysis 


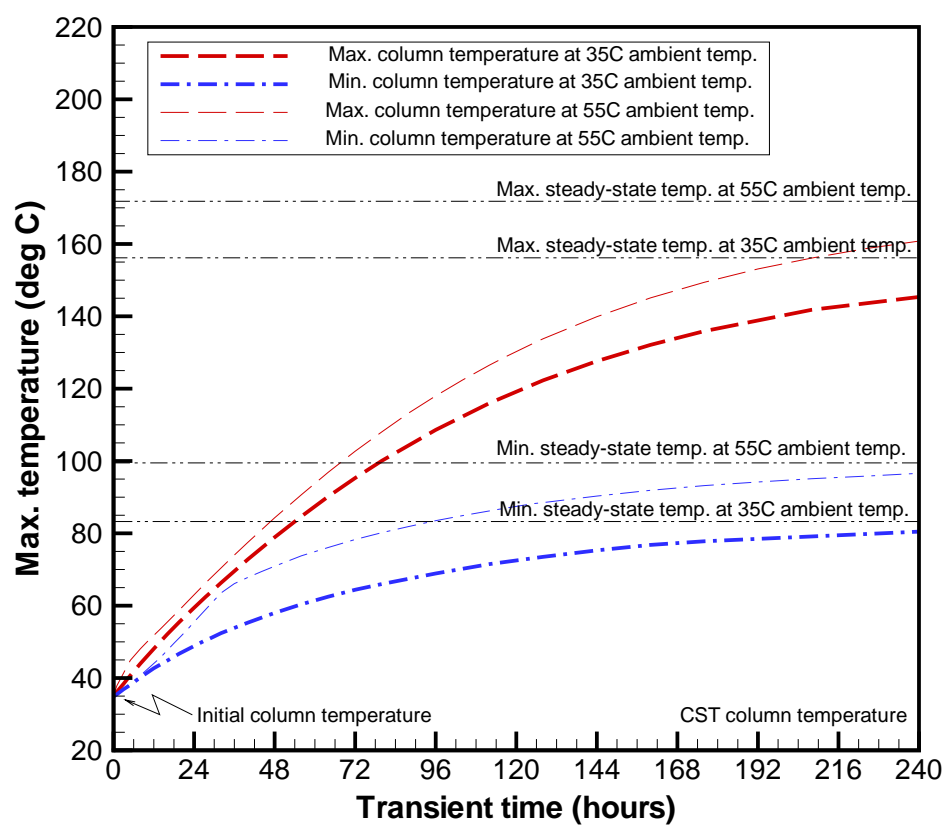

Figure 18. Comparison of transient thermal responses of CST column containing 257 $\mathrm{Ci} /$ liter radioactive heat source between two different ambient temperatures under the Case 1 model

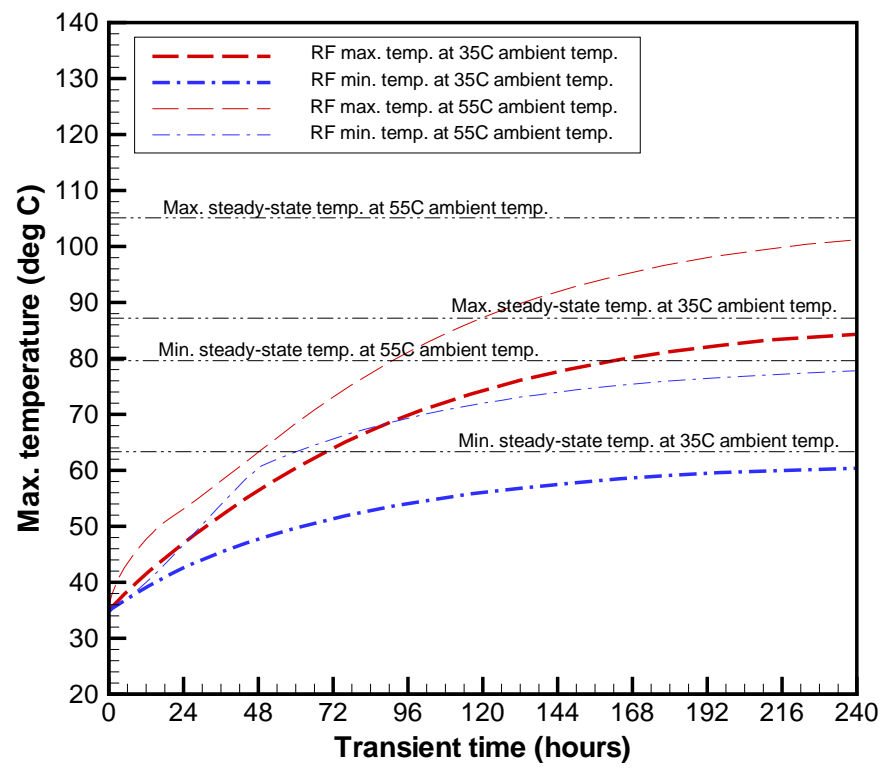

Figure 19. Comparison of transient responses to the fixed RF column containing 133.5 $\mathrm{Ci} /$ liter radioactive heat source between two different ambient temperatures under the Case 1 model 
Table 8. Comparison of transient durations required to reach steady state temperature distributions under the Case 1 modeling conditions

\begin{tabular}{|c|c|c|}
\hline Parameters & CST column & RF column \\
\hline Column cross-sectional area $\left(\mathrm{m}^{2}\right)$ & 0.3575 & 0.3575 \\
\hline Effective thermal conductivity (watts/m-K) & 0.4125 & 0.5987 \\
\hline Thermal diffusivity $\left(\mathrm{cm}^{2} / \mathrm{sec}\right)$ & $1.032 \times 10^{-3}$ & $1.459 \times 10^{-3}$ \\
\hline Theoretical thermal diffusion time (days) & $\sim 40$ & $\sim 28$ \\
\hline Transient duration to reach steady temp. dist. (days) & About 40 & About 28 \\
\hline
\end{tabular}

Table 9. Transient max. temperature results for the Case-I model under 28-in CST/RF columns cooled by natural convection boundary with two different ambient temperatures.

\begin{tabular}{|c|c|c|c|c|}
\hline \multirow{2}{*}{$\begin{array}{l}\text { Transient time } \\
\text { (hours) }\end{array}$} & \multicolumn{2}{|c|}{$\begin{array}{l}\text { CST-Salt solution Column } \\
\left({ }^{\circ} \mathrm{C}\right)\end{array}$} & \multicolumn{2}{|c|}{ RF-Salt solution Column $\quad\left({ }^{\circ} \mathrm{C}\right)$} \\
\hline & $\begin{array}{c}\text { Ambient } \\
\text { temperature } \\
(35.0)\end{array}$ & $\begin{array}{c}\text { Ambient } \\
\text { temperature } \\
\text { (55.0) }\end{array}$ & $\begin{array}{c}\text { Ambient } \\
\text { temperature } \\
(35.0)\end{array}$ & $\begin{array}{c}\text { Ambient } \\
\text { temperature } \\
(55.0)\end{array}$ \\
\hline Initial condition & 35.0 & 35.0 & 35.0 & 35.0 \\
\hline 0.5 & 35.6 & 36.6 & 35.3 & 36.8 \\
\hline 1 & 36.2 & 37.9 & 35.6 & 37.8 \\
\hline 4 & 39.6 & 43.2 & 37.3 & 41.6 \\
\hline 8 & 44.0 & 48.1 & 39.5 & 45.0 \\
\hline 16 & 52.1 & 55.5 & 43.4 & 50.0 \\
\hline 24 (1 day) & 59.4 & 63.0 & 47.0 & 53.1 \\
\hline 32 & 66.3 & 70.4 & 50.3 & 56.4 \\
\hline 48 (2 days) & 78.9 & 84.3 & 56.4 & 63.3 \\
\hline Steady state & 156.0 & 171.6 & 87.6 & 105.1 \\
\hline
\end{tabular}


Table 10. Sensitivity results of the steady state temperatures for different RF resin porosities under the Case 1 model.

\begin{tabular}{|c|c|c|c|}
\hline \multirow{2}{*}{ Parameters } & \multicolumn{3}{|c|}{ RF resin porosity } \\
\cline { 2 - 4 } & $\begin{array}{c}\text { Nominal porosity } \\
(66 \%)\end{array}$ & $\begin{array}{c}\text { 20\% reduced porosity } \\
(0.53 \%)\end{array}$ & $\begin{array}{c}\text { No porosity } \\
(0 \%)\end{array}$ \\
\hline $\begin{array}{c}\text { Effective thermal conductivity } \\
\text { for RF-column (watts/m-K) }\end{array}$ & 0.5987 & 0.5646 & 0.4045 \\
\hline Max. temperature $\left({ }^{\circ} \mathrm{C}\right)$ & 87.6 & 89.2 & 100.1 \\
\hline Min. temperature $\left({ }^{\circ} \mathrm{C}\right)$ & 61.8 & 61.8 & 61.8 \\
\hline
\end{tabular}

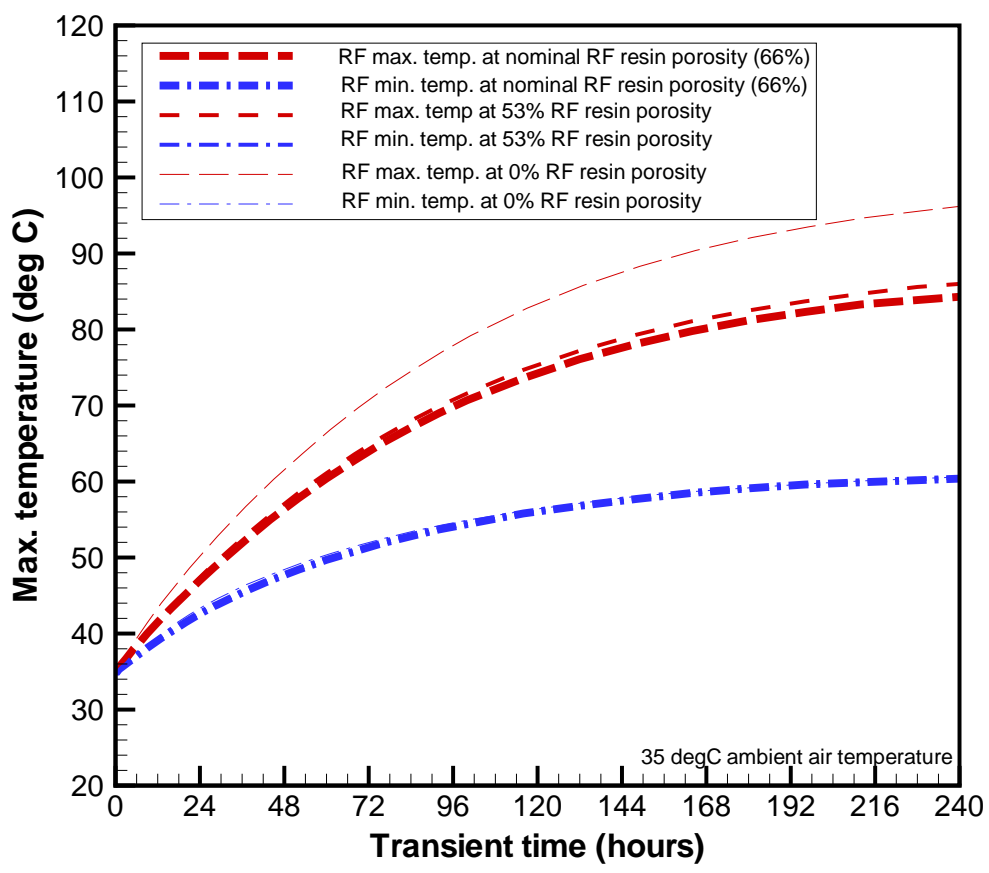

Figure 20. Sensitivity results of different RF resin porosities under the Case 1 model containing RF resin materials 
Table 11. Sensitivity results of the transient maximum temperatures for different RF resin porosities under the Case 1 model.

\begin{tabular}{|c|c|c|c|}
\hline \multirow{2}{*}{$\begin{array}{c}\text { Transient time } \\
\text { (hours) }\end{array}$} & \multicolumn{3}{|c|}{ Maximum RF column temperature ( ${ }^{\circ} \mathbf{C}$ ) } \\
\cline { 2 - 4 } & Nominal porosity (66\%) & $53 \%$ porosity & $0 \%$ porosity \\
\hline 0 & 35 & 35 & 35 \\
\hline 6 & 38.4 & 38.6 & 39.4 \\
\hline 12 & 41.5 & 41.7 & 43.4 \\
\hline 24 & 47.0 & 47.4 & 50.2 \\
\hline 36 & 51.9 & 52.5 & 56.2 \\
\hline 48 & 56.4 & 57.1 & 61.5 \\
\hline
\end{tabular}
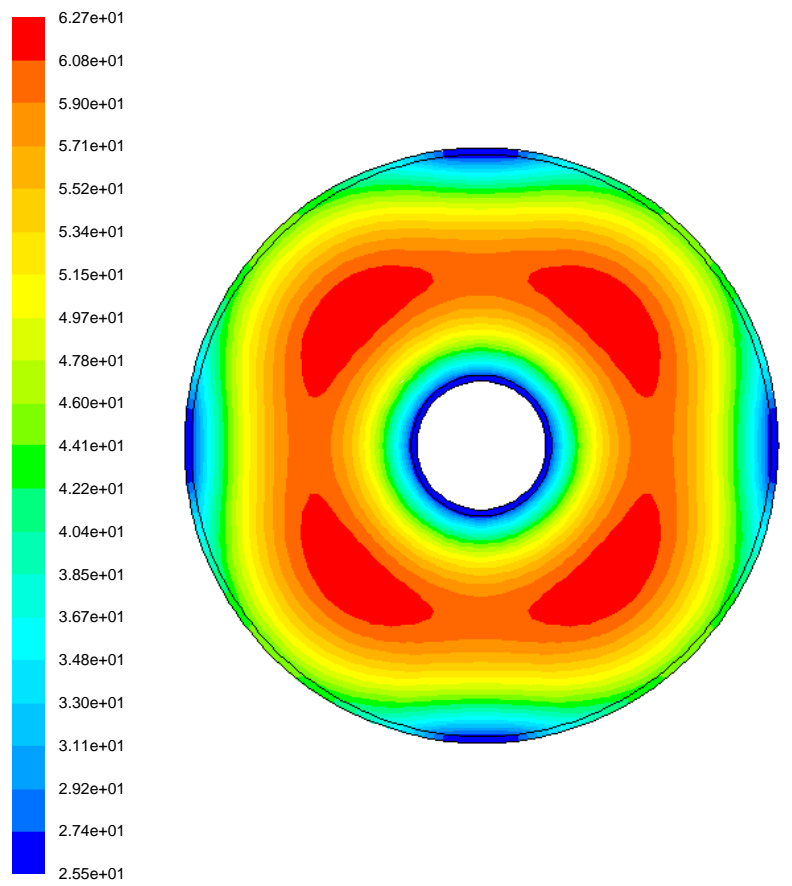

Figure 21. Steady-state temperature distributions for the CST column showing that maximum column temperature is $62.7^{\circ} \mathrm{C}$, and minimum temperature is $25.5^{\circ} \mathrm{C}$ under the boundary conditions of the Case 2 model 


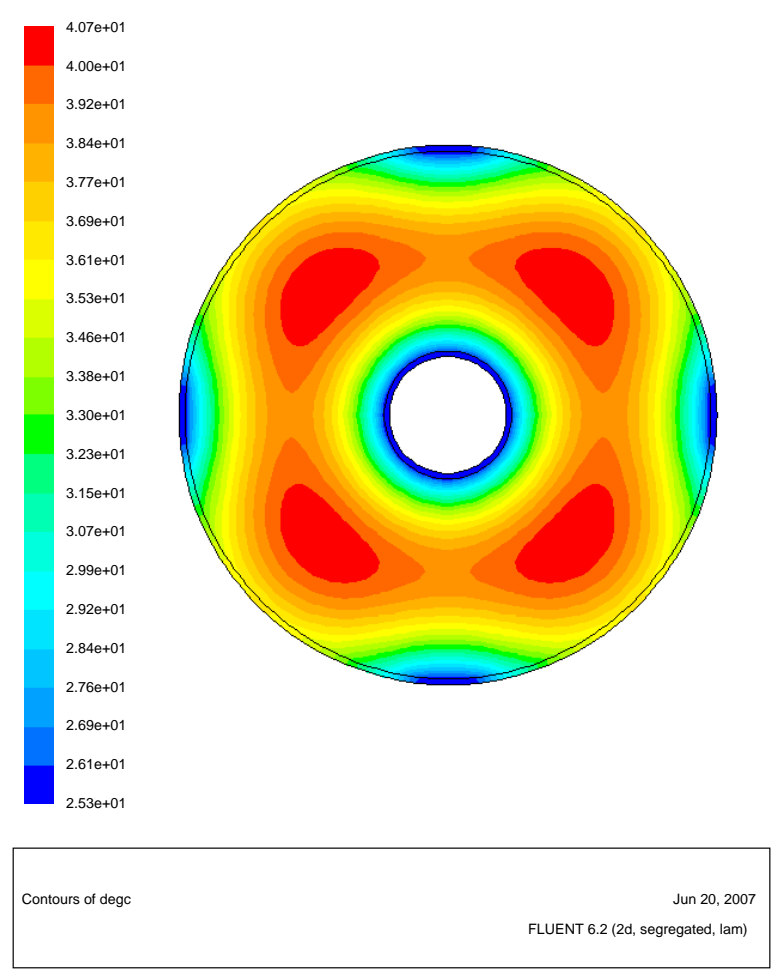

Figure 22. Steady-state temperature distributions for the fixed RF column showing that maximum column temperature is $40.7^{\circ} \mathrm{C}$, and minimum temperature is $25.3^{\circ} \mathrm{C}$ under the boundary conditions of the Case 2 model

Table 12. Summary of steady-state results for the Case 3 model with $35^{\circ} \mathrm{C}$ ambient temperature.

\begin{tabular}{|c|c|c|c|}
\hline \multirow{2}{*}{$\begin{array}{c}\text { Salt Solution } \\
\text { flowrate through } \\
\text { column }\end{array}$} & $\begin{array}{c}\text { Column } \\
\text { height } \\
\mathbf{f t t}\end{array}$ & \multicolumn{2}{|c|}{$\begin{array}{c}\text { Temperature increase between column } \\
\text { inlet and exit through lead column* }\left({ }^{\circ} \mathrm{C}\right)\end{array}$} \\
\cline { 2 - 4 } & 10 & $\mathrm{CST}$ & $\mathrm{RF}$ \\
\hline \multirow{2}{*}{$5 \mathrm{gpm}$} & 15 & 1.1 & 0.56 \\
\cline { 2 - 4 } & 25 & 1.65 & 0.83 \\
\hline
\end{tabular}

Note:*Exit temperature of the salt solution is inlet temperature plus the values in this table. 
Table 13. Summary of sensitivity results for the steady-state bounding models.

\begin{tabular}{|c|c|c|c|c|c|}
\hline \multirow{2}{*}{$\begin{array}{c}\text { Column } \\
\text { systems }\end{array}$} & Models & \multicolumn{2}{|c|}{ Ambient temperature $35^{\circ} \mathbf{C}$} & \multicolumn{2}{|c|}{ Ambient temperature $\mathbf{5 5}{ }^{\circ} \mathbf{C}$} \\
\cline { 3 - 6 } & $\begin{array}{c}\text { Min. bed } \\
\text { temperature } \\
\left({ }^{\circ} \mathrm{C}\right)\end{array}$ & $\begin{array}{c}\text { Max. bed } \\
\text { temperature } \\
\left({ }^{\circ} \mathrm{C}\right)\end{array}$ & $\begin{array}{c}\text { Min. bed } \\
\text { temperature } \\
\left({ }^{\circ} \mathrm{C}\right)\end{array}$ & $\begin{array}{c}\text { Max. bed } \\
\text { temperature } \\
\left({ }^{\circ} \mathrm{C}\right)\end{array}$ \\
\hline \multirow{2}{*}{$\begin{array}{c}\text { CST } \\
\text { column }\end{array}$} & Case 1 & 83.8 & 156.0 & 99.5 & 171.6 \\
\cline { 2 - 6 } & Case 2 & 25.5 & 62.7 & 25.6 & 66.7 \\
\hline \multirow{2}{*}{ RF column } & Case 1 & 61.8 & 87.5 & 79.4 & 105.1 \\
\cline { 2 - 6 } & Case 2 & 25.3 & 40.7 & 25.4 & 45.1 \\
\hline
\end{tabular}

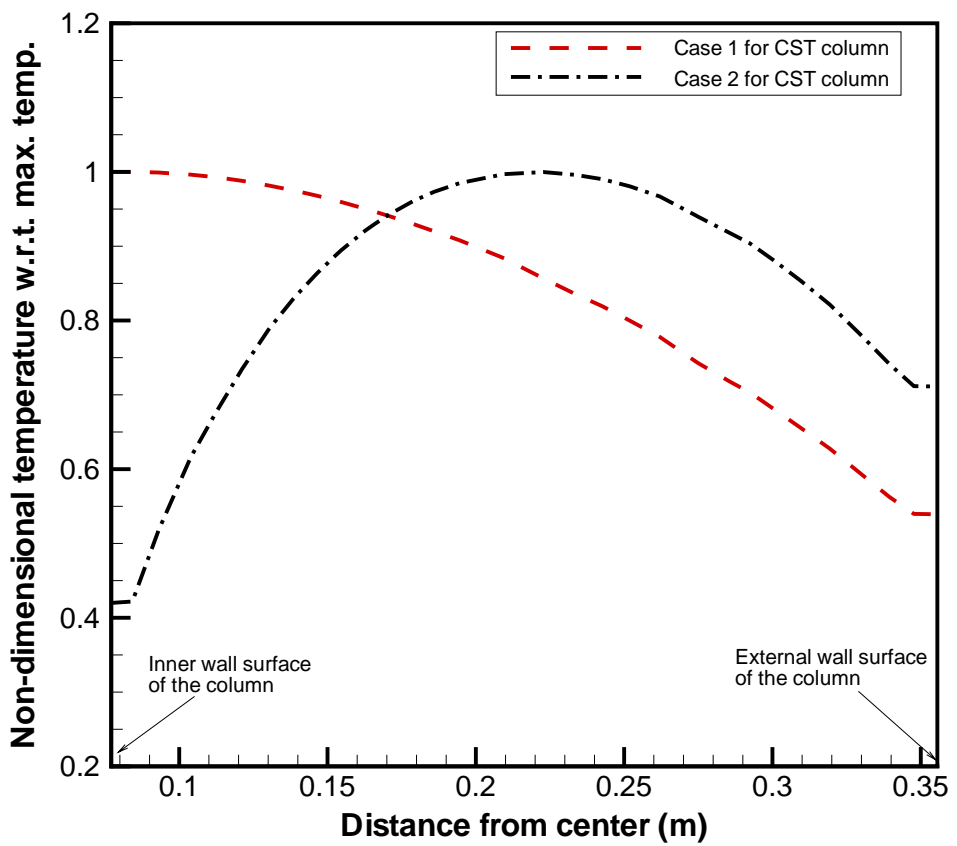

Figure 23. Comparison of the CST columns with and without active coolant systems (Case 1 and Case 2) 

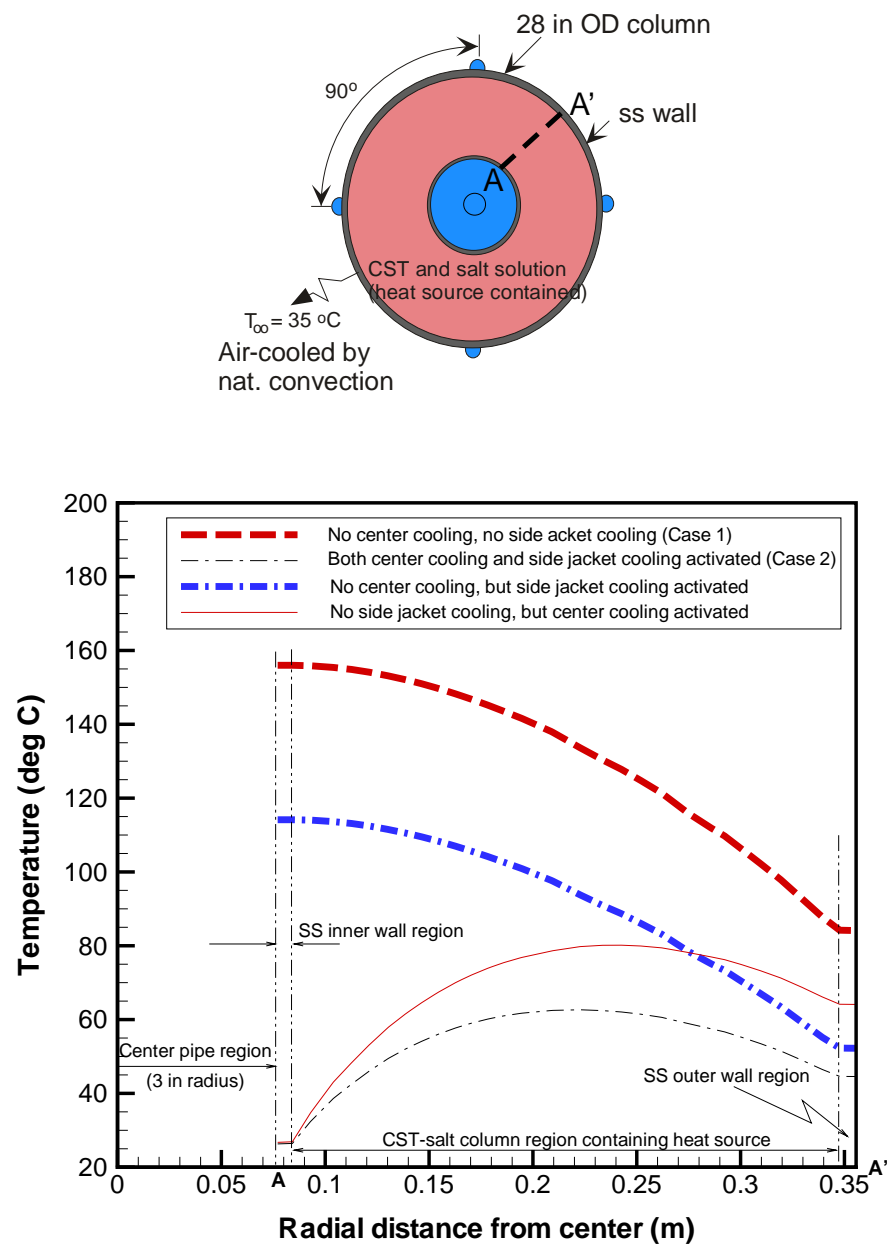

Figure 24. Comparison of steady-state temperature distributions along the radial line A$A^{\prime}$ of the CST columns under combinations of active central and side jacket cooling systems.

Table 14. Comparison of maximum column temperatures loaded with CST material under various operating conditions of cooling system components

\begin{tabular}{|c|c|c|c|c|c|}
\hline \multirow{2}{*}{ Cases } & \multirow{2}{*}{$\begin{array}{l}\text { Total power per } \\
\text { unit height of } \\
\text { CSTcolumn } \\
\text { (watts } / m \text { ) }\end{array}$} & \multicolumn{3}{|c|}{ Cooling system components } & \multirow{2}{*}{$\begin{array}{l}\text { Max. } \\
\text { column } \\
\text { temp. } \\
\left({ }^{\circ} \mathrm{C}\right)\end{array}$} \\
\hline & & $\begin{array}{l}\text { Center cooling } \\
\text { pipe }\end{array}$ & $\begin{array}{l}\text { Side cooling } \\
\text { jackets }\end{array}$ & Side dry wall & \\
\hline Case 1 & 455.0 & Not active & Not active & $\begin{array}{c}\text { Natural } \\
\text { convection }\end{array}$ & 156 \\
\hline Case 2 & 455.0 & Active & Active & $\begin{array}{c}\text { Natural } \\
\text { convection }\end{array}$ & 63 \\
\hline \multirow{2}{*}{$\begin{array}{l}\text { Sensitivity } \\
\text { runs }\end{array}$} & 455.0 & Active & Not active & $\begin{array}{c}\text { Natural } \\
\text { convection }\end{array}$ & 80 \\
\hline & 455.0 & Not active & Active & $\begin{array}{c}\text { Natural } \\
\text { convection }\end{array}$ & 114 \\
\hline
\end{tabular}




\section{Conclusions}

Transient two-dimensional heat conduction calculations have been performed to assess the thermal properties of cesium-saturated CST- and RF-packed ion exchange columns immersed in $6 \mathrm{M} \mathrm{Na}^{+}$salt solution under the baseline SCIX design. For Case 1, steadystate and transient temperature profiles within the cylindrical columns were determined for natural convection cooling under no process flow situations. This is considered a bounding conservative case. For Case 2 steady-state calculations were conducted to determine the maximum column temperatures under no process flow conditions but with active cooling (mixed natural/forced convection cooling). Case 3 quantified the steady state temperature responses (system heatup) under nominal operating conditions with 5 gpm liquid flow.

From the present modeling results, the main conclusions are:

- Under no process flow conditions with an inactive cooling system (Case 1) and columns suspended in unventilated ambient air, CST columns reach boiling temperatures within approximately 5 and 6 days for 55 and $35^{\circ} \mathrm{C}$ air temperatures, respectively. With $35^{\circ} \mathrm{C}$ ambient air under Case 1 conditions, the maximum temperature of the CST column reaches $60^{\circ} \mathrm{C}$ within $\sim 1$ day and $80^{\circ} \mathrm{C}$ within $\sim 2$ days. The temperature limit for CST stability is believed to be in the temperature range $50-80^{\circ} \mathrm{C}$.

- Cesium-saturated RF-salt solution columns do not reach boiling temperatures under any conditions. The maximum temperatures of RF columns under Case 1 and 2 conditions are $87.6^{\circ} \mathrm{C}$ and $40.1^{\circ} \mathrm{C}$, respectively. The temperature limit for RF stability is believed to be $65^{\circ} \mathrm{C}$.

- Under no process flow conditions with a fully active cooling system (Case 2) and columns suspended in unventilated ambient air at $35^{\circ} \mathrm{C}$, CST columns reach a maximum temperature of $63^{\circ} \mathrm{C}$. Maximum steady-state temperatures predicted for CST columns with partial cooling involving only the central cooling pipe and only the water jackets are 80 and $114^{\circ} \mathrm{C}$, respectively.

- The 6-in water cooling pipe located at the center of the column provides the most effective cooling mechanism under stagnant column conditions (cooling capacity $-33 \%$ of total heat load).

- Salt solution flow through the columns (Case 3) provides the most effective overall heat transfer mechanism. Maximum temperature differentials within the columns were less than $5^{\circ} \mathrm{C}$ in all cases with a liquid phase flow rate of $5 \mathrm{gpm}$. 


\section{$5 \quad$ References}

1. T. M. Punch, "Small Column Ion Exchange Performance Modeling", Technical Task Request, HLE-TTR-2007-014, Rev. 1 (March 2007).

2. S. Y. Lee, Task Plan for Thermal Modeling of Ion Exchange Columns with CST and Spherical RF resins", WSRC-TR-2007-00191, Rev. 0 (May 2007).

3. Drawing No. 1760-M-204 (SCIX IX Module Vessel Assembly \& Details).

4. S. Y. Lee, "Heat Transfer Analysis For A Fixed CST Column", WSRC-TR-200300416, (October 2003).

5. B. B. Spencer, H. Wang, K. K. Anderson, "Thermal Conductivity of IONSIVIE911TM Crystalline Silicotitanate and Savannah River Waste Simulant Solutions", ORNL/TM-2000/285, Oak Ridge National Laboratory, TN, (2000).

6. P. A. Taylor, C. H. Mattus, "Thermal and Chemical Stability of Baseline and Improved Crystalline Silicotitanate", ORNL/TM-2001/165 (December 2001).

7. C. E. Duffey, D. D. Walker, "Radiolytic, Thermal, and Physical Degradation Testing of Spherical Resorcinol-Formaldehyde Resin (U)" WSRC-TR-2005-00075, Rev. 0 (July, 2006).

8. F. G. Smith, III, "Modeling of Ion-Exchange for Cesium Removal from Dissolved Saltcake in SRS Tanks 1-3, 37 and 41", WSRC-STI-2007-00315 (June 2007).

9. Fluent ${ }^{T M}$, Fluent, Inc. (2003).

10. S. Y. Lee, "Heat Transfer Calculations for a Fixed CST Bed Column", WSRC-TR2000-00522 (December 2000).

11. D. T. Bostick and W. V. Steele, "Thermal and Physical Property Determination for IonsivIE-911 Crystalline Silicotitanate and Savannah River Waste Simulant Solutions", WSRC-TR-99-00323, Rev. 0 (August 1999).

12. S. Y. Lee, "Heat Transfer Calculations for Normal Operations of a Fixed CST Bed Column", WSRC-TR-2001-00255 (May 2001).

13. W. M. Kays and M. E. Crawford, Convective Heat and Mass Transfer, Second Edition, McGraw-Hill Book Company, New York (1980).

14. J. P. Holman, Heat Transfer, $4^{\text {th }}$ edition, McGraw-Hill Book Company, New York (1976).

15. A. J. Chapman, Heat Transfer, Third Edition, Macmillan Publishing Co., Inc,, (1974).

16. C. Y. Warner and V. S. Arpaci, "An Experimental Investigation of Turbulent Natural Convection in Air at Low Pressure along a Vertical Heated Flat Plate", International Journal of Heat and Mass Transfer, Vol. 11, pp. 397-406 (1968).

17. J. Jerrell, S. Y. Lee, and A. Shadday, "Thermal Analysis of the Failed Equipment Storage Vault System (U)", WSRC-TR-95-0288 (1995).

18. R. Krupiczka, "Analysis of Thermal Conductivity in Granular Materials", International Chemical Engineering, Vol. 7, No. 1, pp. 122-144 (1967).

19. J. A. Pike and R. A. Jacobs, "Interoffice Memorandum: Input for Heat Transfer Calculations for a Fixed Bed CST Ion Exchange Column", HLW-SDT-2000-00456, Rev. 0, October 30, 2000.

20. W. M. Rohsenow and H. Y. Choi, Heat, Mass, and Momentum Transfer, PrenticeHall, Inc., New Jersey (1961). 
21. F. W. Dittus and L. M. E. Boelter, Engineering Publication vol. 2, pp. 443, University of California (1930).

22. R. H. Perry and C. H. Chilton, Chemical Engineers' Handbook, McGrawHill Book Company, New York (1973). 